\title{
FIXING CAPITAL GAINS: SYMMETRY, CONSISTENCY AND CORRECTNESS IN THE TAXATION OF FINANCIAL INSTRUMENTS
}

David F. Bradford

Working Paper 5754

\section{NATIONAL BUREAU OF ECONOMIC RESEARCH 1050 Massachusetts Avenue Cambridge, MA 02138 \\ September 1996}

This is a revised version of a paper presented to the Tax Law Review Colloquium on Financial Instruments, New York University, New York, May 22, 1995 and will be published in a forthcoming issue of the Tax Law Review. Comments of colloquium participants and subsequent helpful comments from Alan Auerbach, Joseph Bankman, Louis Kaplow, Mark Gergen, Diane Ring, Robert Scarborough, Deborah Schenk, Daniel Shaviro, and Alvin Warren are gratefully acknowledged. In addition, I would like to thank the John M. Olin Foundation for support of the research underlying this paper. This paper is part of NBER's research program in Public Economics. Any opinions expressed are those of the author and not those of the National Bureau of Economic Research or any other institution.

(C) 1996 by David F. Bradford. All rights reserved. Short sections of text, not to exceed two paragraphs, may be quoted without explicit permission provided that full credit, including $\mathbb{C}$ notice, is given to the source. 
NBER Working Paper 5754

September 1996

\title{
FIXING CAPITAL GAINS: SYMMETRY, CONSISTENCY AND CORRECTNESS \\ IN THE TAXATION OF FINANCIAL INSTRUMENTS
}

\begin{abstract}
An enormous amount of effort and ingenuity has been addressed to patching holes in the income tax attributable to realization accounting. A classic instance of the problem is the headaches created by capital gains, whereby the taxpayer can choose to postpone recognition of gain and accelerate recognition of loss (a practice known as cherry picking). Nowhere are the inconsistencies that result from realization accounting more pronounced than in the taxation of financial instruments, especially "derivatives" of familiar securities. This paper sets forth the requirements for income measurement rules based on realization that are "linear" in the sense that doubling a person's transactions will double the taxable income, and adding one set of transactions to another will result in the sum of the associated income. Under present realization conventions, the tax law cannot be linear because there would then be no limit on tax arbitrage profit via variations on borrowing with deductible interest and lending tax exempt. To focus on the principles, the paper assumes transactions are costless. In that case, it is shown that to deal with the intertemporal aspect of the problem requires virtually universal imputation of taxable interest income to basis (the taxpayer's cost of an asset). To deal with the risk aspect of the problem (lock-in and cherry picking) requires simply that the effective rate of tax on gains and losses be the same (not necessarily equal to the rate on intertemporal returns). A new method is proposed that satisfies the requirements for linear income measurement. It is shown that the retroactive taxation of gain devised by Alan Auerbach is a special case of the new approach (involving a zero effective rate of tax on gains and losses).
\end{abstract}

\author{
David F. Bradford \\ Woodrow Wilson School \\ Princeton University \\ Princeton, NJ 08544-1013 \\ and NBER \\ bradford@princeton.edu
}




\section{Fixing Capital Gains: \\ Symmetry, Consistency and Correctness \\ in the Taxation of Financial Instruments}

David F. Bradford

$8 / 23 / 96$

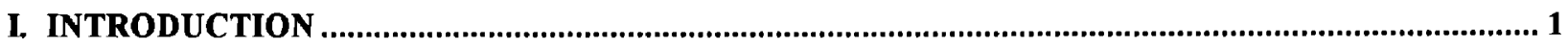

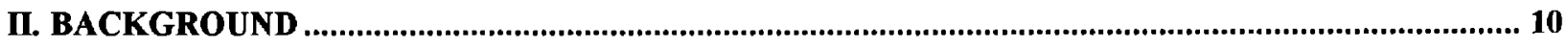

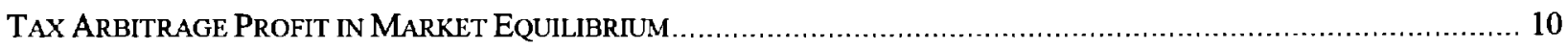

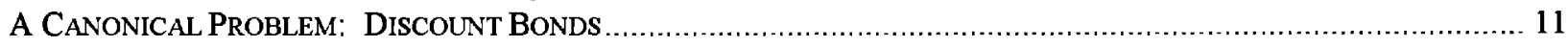

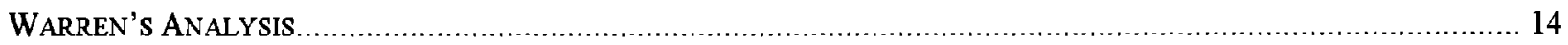

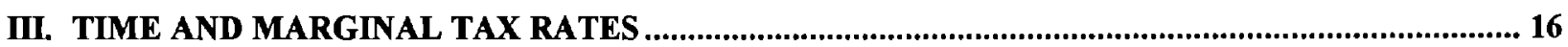

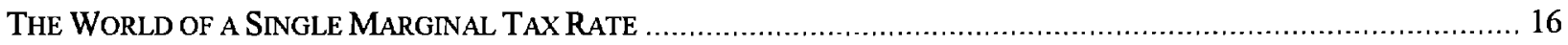

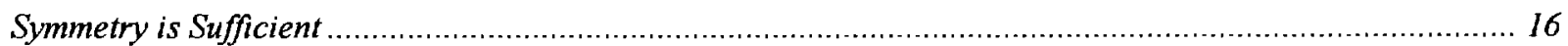

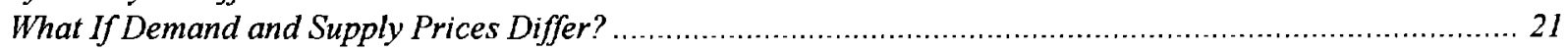

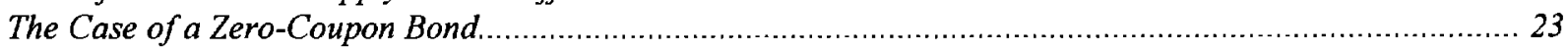

Under General Conditions, Symmetry is Necessary .......................................................................... 24

Present Realization Approach to Capital Gains Taxation Fails the Symmetry Test .................................... 26

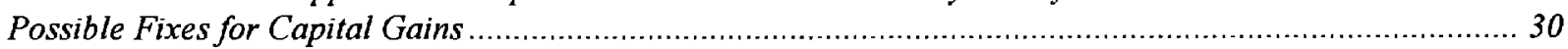

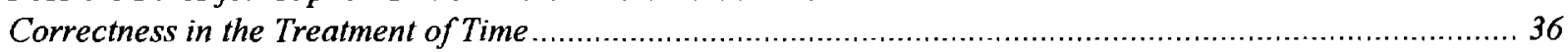

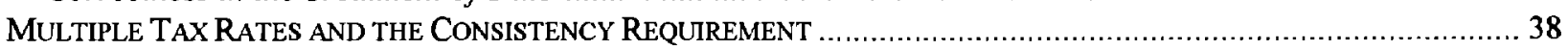

OID Rules Illustrate the (Strictly Speaking, Unsuccessful) Quest for Consistency ..................................... 41

Present Realization Approach to Capital Gains Taxation Fails the Consistency Test .................................. 42

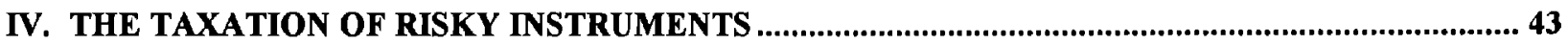

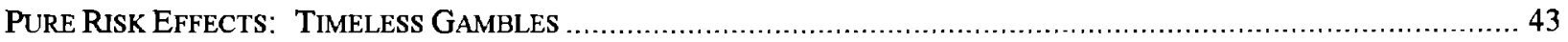

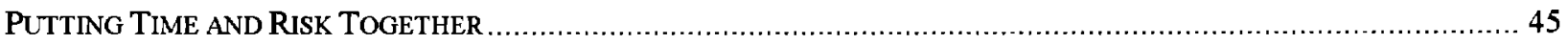

Tax Rules to Prevent Unlimited Tax Arbitrage Profit ........................................................................ 47

V. A GENERAL PROCEDURE FOR TAXING FINANCIAL INSTRUMENTS ....................................... 53

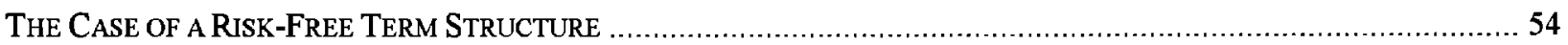

The Proposed Approach When There Is No Cash Flow before Realization ............................................... 54

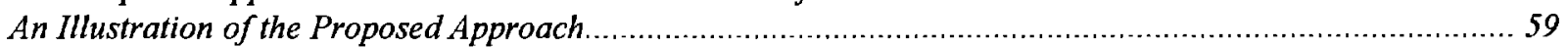

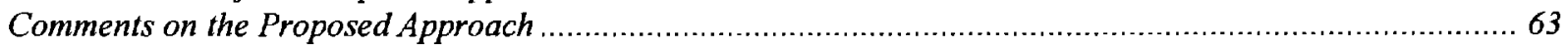

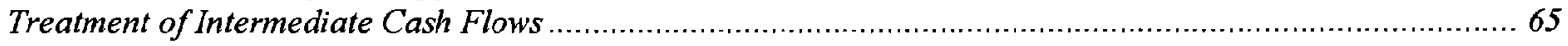

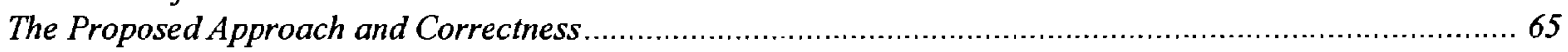

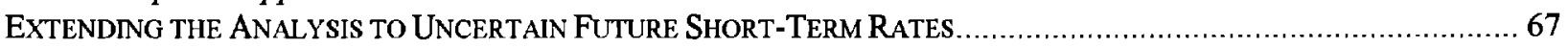

The Term Structure of Interest Rates with Uncertain Short-Term Rates .................................................. 67

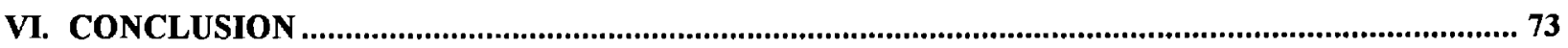

APPENDIX: A CONTINUOUS-DISCOUNTING VERSION OF THE PROPOSED RULES....................... 75

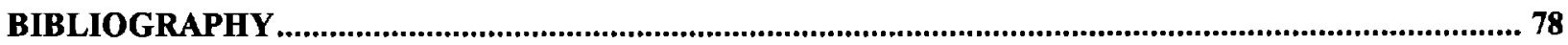




\author{
Fixing Capital Gains: \\ Symmetry, Consistency and Correctness \\ in the Taxation of Financial Instruments \\ David F. Bradford ${ }^{*}$
}

\title{
I. Introduction
}

This paper was stimulated by reading "Financial Contract Innovation and Income Tax Policy," by Alvin C. Warren (1993), dealing with certain fundamental problems in income tax accounting for financial instruments. Subsequent browsing in the burgeoning literature to which Warren's paper contributes (see Bibliography) has shown me there is a much about the income tax treatment of financial instruments that I do not know. Some of what is set forth in this paper will be in the nature of review for serious thinkers on this subject. I believe, however, there is something new in my conclusions.

In his paper Warren develops the difficulties created for the income tax system by its reliance on a combination of different rules applicable to "fixed" and "contingent" returns to the holders of financial instruments. The fixed returns are taxed according to a generalization of the long-standing treatment of periodic interest. That is, there is

Professor of Economics and Public Affairs, Princeton University, Adjunct Professor, New York University School of Law, Research Associate, National Bureau of Economic Research and Adjunct Scholar, the American Enterprise Institute. This is a revised version of a paper presented to the Tax Law Review Colloquium on Financial Instruments, New York University, New York, May 22, 1995 and will be published in a forthcoming issue of the Tax Law Review. Comments of colloquium participants and subsequent helpful comments from Alan Auerbach, Joseph Bankman, Louis Kaplow, Mark Gergen, Diane Ring, Robert Scarborough, Deborah Schenk, Daniel Shaviro, and Alvin Warren are gratefully acknowledged. In addition, I would like to thank the John M. Olin Foundation for support of the research underlying this paper. Views expressed are my own and should not be taken as representing any institution. 
inclusion in the taxable income of the holder and a deduction by the issuer of the equivalent of periodic interest payments, using a "yield to maturity" calculated from the instrument as the basis for specifying the applicable interest rate. The contingent returns are taxed upon a realization event, with the difference between cost basis and realized amount included in the income of the holder (deducted if it is a loss). Warren calls the first the "yield to maturity" approach and the second the "wait and see" approach. A third approach, discussed by Warren, is the mark-to-market method. For the case of an instrument that is held throughout a period during which it gives rise to no cash flows, the holder includes in income the increase in the instrument's market value over the period. (If there is a cash flow during the period, it is added to the increase in market value. This principle would apply equally to asset and liability sides. For an instrument with a party and counterparty, to each inclusion by one party would correspond a deduction by the counterparty.)

The main challenge Warren sees is in the taxation of contingent returns.

Postponement of income until realization gives rise to familiar problems due to a differential between the treatment of accruing and deferred income. Having convincingly demonstrated the limitations of the established approaches to dealing with this differential, Warren offers in conclusion the following provocative observation:

Serious consideration should [therefore] be given to reducing the differential by taxing at least some contingent returns in accordance with a formula, such as the retrospective allocation of gain or the imputation of interest at a standard rate. Although not without precedent, development of a formulaic approach would be a significant change in the concept of realization. Such a change may be necessary, for the traditional concept no longer seems adequate to deal with innovative financial contracts. 
In this paper I take yet another look at the taxation of financial instruments. To isolate certain income-measurement problems, I focus on a world with no transactions costs. This setting throws into particular relief that the critical difficulty is dealing consistently with the intertemporal aspects of transactions. This is well known in a sense; timing is central to an income tax. But I shall argue that the difficulties are more serious than is commonly realized, and the constraints on workable rules in the no-transactionscost world are extremely confining. Imputation of interest (at a specific, if not a "standard" rate) is the key to isolating the timing problem. By contrast, there are surprising degrees of freedom in dealing consistently with contingency.

Original issue discount (OID) bonds provide a useful illustration of what I mean by the purely intertemporal problem, since taxing them does not obviously raise issues of contingency or collateral issues, such as character. The yield-to-maturity method of assigning taxable income attempts to produce consistency between the consequences of holding an OID bond and holding an otherwise similar instrument that generates periodic interest payments. If we take as the standard the mark-to-market method, which does not depend at all on transactions, the yield-to-maturity method may accomplish a reasonable approximation in practice. But to understand or deal with more complex cases, it is helpful to be clear that, strictly speaking, neither the yield to maturity nor the other familiar rules that rely on either actual or imputed cash flows between parties to a financial instrument precisely solve the intertemporal consistency problem. This is partly because the yield to maturity is typically an amalgam of the shorter-term interest rates that represent the "proper" measure. It is also because longer-term instruments almost inevitably incorporate some degree of contingency. 
As I shall argue, to eliminate differentials in taxation of the purely intertemporal effects of financial instruments in a transactions-based system, one needs to start with the taxation of one basic set of instruments that accomplishes exchange of dollars at one time for dollars at another time. I take as what I regard as the natural choice the taxation of simple, one-period loans that have no risk of default. ${ }^{1}$ The taxation of these elementary transactions then restricts the possibilities for taxing other transactions without introducing "complications." Chief among the complications are rules such as the limit on the deductibility of realized capital losses, which I describe as violations of linearity (to be explained shortly).

Accordingly, my approach in this paper is to examine the restrictions on the income measurement rules applicable to financial instruments implied by the requirement that the rules be linear. More precisely, I focus on the rules that must apply to a "bilateral financial instrument." I mean by this term a bilateral contract that consists entirely in the specification of cash payments to be made by a party to a counterparty. So, for present purposes, an ordinary bond is a bilateral financial instrument but a property lease is not, since the latter provides that one party deliver certain services in return for cash payments by the other party.

The reason for restricting attention to bilateral financial instruments is not that I believe it would make sense for there to be a special regime for them. On the contrary, I take for granted that whatever income measurement rules exist should apply as well to the restricted class of transactions in bilateral financial instruments. Bilateral financial

${ }^{1}$ Such instruments may be subject to inflation risk, however. As I shall emphasize, 
instruments are the focus here because they provide the opportunity for the tax arbitrage transactions that call forth complicating fiscal defenses.

In an income tax based on transactions, the consequence of a particular sequence of transactions over time is a sequence of taxable income amounts. ${ }^{2}$ The rules that translate the transactions into taxable incomes have the property of linearity in the sense used in this paper if, when applied to the combination of two sequences of transactions (adding them together), they produce the combination (the period-by-period sum) of the corresponding taxable income sequences. Similarly, if every element of a sequence of transactions is multiplied by some number (doubling everything, for example), the resulting sequence of taxable incomes is multiplied by the same number. In particular, if everything is multiplied by negative one, the taxable income sequence is reversed as well, rendering deductible losses taxable gains and taxable gains deductible losses. ${ }^{3}$

Linearity is a desideratum of a tidy tax system. Violations of linearity tend to produce inefficiencies and anomolies, as when an investor is unable to deduct a loss that has no tax motivation. Nonlinearities also typically imply a reward to careful tax planning, and add to tax complexity. The U.S federal income tax rules incorporate many violations of linearity, however. I use the limitation on the deductibility of capital losses as representative. A taxpayer whose net capital losses in a given year exceed $\$ 3000$ is obliged to carry forward the excess, to be netted against possible future gains. Doubling

consistency, not correctness, is the objective.

2 A transaction may itself be more or less complex. So, for example, acquisition of a discount bond gives rise under the rules to a sequence of increments to future taxable income. If the bond is sold, the sequence is revised in a way specified by the rules. 
everything about the transactions of a taxpayer who is right at the $\$ 3000$ capital loss limit will result in a net $\$ 6000$ loss. Since the extra loss cannot be deducted currently, the consequence is generally that the taxable income will not be doubled, in violation of linearity. Another example is the limitation on the deductibility of investment interest. Adding some dividends to a person's transactions will increase the tax due from a taxpayer not up against the limitation, but will not increase the tax due from one who is. As will become clear, if it is not obvious, both of these nonlinearities serve to bound tax arbitrage profit opportunities that would not otherwise be self-limiting. ${ }^{4}$

In the interest of sharpening understanding, I work in this paper with some extreme assumptions. I have mentioned the most significant extreme assumption I make, that there are no transactions costs. Arguably, it is transactions costs that protect the income tax from much more extensive tax arbitrage than currently occurs. Assuming them away removes the protection and exposes the income measurement problems. I also assume (perhaps this is implied by the absence of transactions costs) a taxpayer can costlessly take any zero-value position, borrowing to buy a security, for example.

There is a practical as well as an analytical reason to investigate the frictionless world. One of the most striking developments in financial markets in recent years has been a steady decline in transactions costs, reflected in the proliferation of new instruments. The paper thus can be read as exploring problems that we can expect to get worse, absent redesign of the rules.

3 This definition is very close to Strnad's (1994, p. 576).

${ }^{4}$ For a comprehensive analysis of the role and effect of loss limitations to obstruct tax arbitrage, see Scarborough (1993). 
A subtheme of the paper is correctness, about which I have two general points in mind. First, it is quite possible for rules that fail to produce an accurate measure of a period's income (in the sense of change in accrued wealth) nevertheless to produce a result that is economically equivalent to accurate measurement from the point of view of the taxpayer. An example would be some sort of look-back calculation of interest accrued on a discount bond. Second, it may be essential that income measurement rules involving different sorts of instruments be consistently related to one another, even if the rules fail to measure income correctly. The underlying program of most rule-writing for financial instruments (for example, the treatment of original issue discount) can be described as seeking consistent treatment with that applied to plain vanilla interest. But consistency in this sense in the treatment of different financial instruments is not the same as correctness of the treatment of any of them. Plain vanilla interest may be a poor approximation to the real return on the associated asset.

The difference is due to inflation. It is conventionally accepted that modest inflation -- $2 \%$ to $3 \%$ per year -- can safely be neglected in the tax system. But this paper's emphasis on the critical role of time, and not risk, invites the observation that the real return to pure waiting (as opposed to risk-taking) in U.S. financial markets over the past few decades has been about $0.5 \%$ per year. ${ }^{5}$ If this is a reasonably close approximation to the pure intertemporal return, a very modest income tax rate applied to nominal interest of $2.5 \%$ to $3.5 \%$ renders the real, after-tax return negative. It is

5 This is the average real rate of return on U.S. Treasury bills. See R. G. Ibbotsen Associates (1995). 
somewhat ironic that great effort is applied to assure that all transactions are treated equally badly.

The most important instance in this paper of rules that produce a correct result (in the sense of equivalence, from the taxpayer's point of view, to taxing accruing wealth) arises in connection with taxation of risky instruments. If the outcome of a risky situation is a gain of $\$ 1$ by one party to a financial instrument and an offsetting loss of $\$ 1$ to the counterparty, an accurate measure of wealth change would add $\$ 1$ to the income of the winner and subtract $\$ 1$ from the income of the loser. I think most of the rule-writing effort with regard to contingent returns seeks correctness in this sense. My conclusion is that the objective is unimportant in the context of risk-taking because of the flexibility people have to adjust their financial positions. It is important that a taxpayer's gains and losses on a given asset be taxed at the same rate, but not necessarily at the rate applied to other transactions. It is thus possible to identify rules that are economically equivalent to taxing a taxpayer's change in wealth but make no pretense at producing a correct measure of it.

The body of this paper is divided into four parts (preceded by this introduction and followed by a brief conclusion). In Part II, I present a background discussion of the concept of tax arbitrage and review Warren's findings. In Part III, I focus narrowly on the problem presented by time, in the absence of risk. Much recent writing, including Warren's paper, emphasizes the central role of risk. This emphasis is clearly justified. It may, however, not be clear quite how time and risk interact to challenge the implementation of an income tax. The object of Part III is then to restate the problems of taxing purely intertemporal transactions. I found it desirable, and probably necessary, to 
write down my own version of this material in order to address with precision the problem of dealing with contingency. The main conclusion that I reach in Part III that may be somewhat new or controversial is the one already mentioned. Strictly speaking, there is very little flexibility about the "right" way to tax intertemporal transactions. The yield to maturity method, for example, is "wrong." The practice of using the "applicable federal rate" for imputing interest to positions of different maturity is another example of an approach that is, strictly speaking, wrong. Taxation based on realization requires either imputing interest to basis at the going rates during the holding period, or what amounts to the same thing, imposing a tax on realization that treats the proceeds as having been accumulated at the interest rates prevailing during the holding period. (I refer to the latter approach as the Auerbach method, since Alan Auerbach spelled it out in a 1991 article.)

In Part IV, I suggest that the taxation of risk per se poses surprisingly few problems. It does, however, upset the efficacy of the method of imputing interest to basis as a way of perfecting a realization system. Instead, of the approaches that have been considered, only the Auerbach method remains as a possibility.

In Part V, I describe an alternative approach to taxing contingent returns using realization accounting. It eliminates any tax-induced timing advantages or disadvantages from realization. The key idea is that the rate applicable to gains in excess of the current interest rate may be set freely, but it must be set in advance of any information about the extent of any such gains. As it turns out, the Auerbach method is a special case of the alternative approach, which offers considerably greater flexibility for the design of policy. The title of the paper suggests both reach, "fixing capital gains," and narrowness of focus on financial instruments. As I have indicated, financial instruments are central in 
the paper because they raise most sharply problems due to inconsistency in the taxation of different forms of return. But, with provisos that I discuss in Part V, I believe that the method I have devised for taxing contingent returns on financial instruments could be extended to contingent returns generally.

\section{Background}

$\underline{\text { Tax Arbitrage Profit in Market Equilibrium }}$

The term "arbitrage" refers to the activity of buying and selling the same thing in different markets, and a profit results if the price paid to buy is below that received on the sale (by enough to cover the costs of arranging the pair of transactions). One could mean more than one thing by the term "tax arbitrage." For example, some would describe as tax arbitrage, the activity of borrowing with deductible interest to purchase a business asset that offers accelerated depreciation. In this paper the focus is on tax arbitrage using financial instruments. The instrument itself specifies cash flows between the parties. An opportunity for tax arbitrage profit exists when there is a pair of instruments (or pair of packages of instruments) that are identical in their cash flows but differ in the associated flows of taxable income. Then, if the tax system is linear, by entering into exactly offsetting positions in the two instruments, taxpayers may be able to reduce their taxes.

The opportunity for arbitrage profit of any kind is inconsistent with equilibrium. So the potential for tax arbitrage must be eliminated by some combination of adjustments in asset prices, changes in effective marginal tax rates (including changes resulting from

${ }^{6}$ On the definition of tax arbitrage, Warren (1993, p. 471) cites Steuerle (1985), Bradford (1980), and Warren (1985). 
such rules as limits on deductions, so that the marginal rate on an extra dollar of the deduction in question is effectively zero) and increases in transactions costs.

\section{A Canonical Problem: Discount Bonds}

The tax treatment of a zero-coupon discount bond provides a handy canonical example of tax arbitrage. In the old days, a cash basis taxpayer holding a zero-coupon discount bond had no inclusion in taxable income until the bond paid off at maturity, at which point the holder included the difference between the amount received and basis, the amount paid for the bond. By contrast, the holder of a bond that pays interest currently was, and still is, obliged to bring into taxable income the successive interest payments. Consider the problem posed by this treatment of the two sorts of instruments. For purposes of this discussion, assume all the taxpayers in question are on a cash basis. Also, since the concern here is with timing, not character, assume no difference between ordinary and capital gains rates.

In the absence of taxes, neglecting transactions costs (the cost of arranging the arbitrage) and ignoring possible unpredictable variations in the short-term interest rates (to which I return below), we know an investor who undertakes a sequence of investments in short-term bonds paying ordinary interest, always reinvesting the principal and interest, can achieve exactly the same pattern of net period-by-period cash flows as the holder of the zero-coupon discount bond. There are two important points to emphasize about the equivalence between the two positions, the zero-coupon discount bond and the program of investment in ordinary one-period loans with reinvestment: First, with a little cleverness, two parties could enter into an agreement to exchange one for the other in such a way that no cash flow ever occurred between them. In all but superficial details, 
this would be a pure arbitrage transaction -- buying and selling the exact same thing. Second, in the capital markets this equivalence would be recognized in that the two positions would have the same value. They could be exchanged at arm's length, without any cleverness between two parties.

With the tax rules as assumed, the exact equivalence of the two positions is upset when taxes are taken into account. The zero-coupon discount bond delivers a better flow of taxable income to the holder because the gain is not taxed until maturity. Relative to the taxation of the duplicating sequence of short-term bond transactions, the zero-coupon discount bond is tax-favored to the holder.

If the timing of the inclusions of the holder were identical to the timing of the deductions of the issuer, the tax advantage to the holder would be matched by a disadvantage to the issuer. A simple solution to the OID problem might then seem to be to let the market absorb the tax aspects of transactions.

The problem with this solution is that the extent of the tax advantage to the holder of the zero-coupon discount bond depends on the holder's marginal tax rate, and the extent of its disadvantage to the issuer depends on the issuer's marginal tax rate. (A tax exempt entity is functionally the same as a taxable entity with zero marginal tax rate.) If the marginal tax rates of holder and issuer were the same, the advantage of the tax-favored instrument to the holder would be just balanced by its disadvantage to the issuer. In that case, we would expect the market-determined terms of the two types of instruments to correct for their different tax attributes. Through adjustment in the prices of debt contracts, the implied after-tax yields would be equated, regardless of the cash-flow 
pattern involved, and regardless of the relationship of the taxation of any one of them, taken in isolation, to any particular income concept.

The possibility of such an adjustment illustrates the point that correctness of the treatment of a transaction is not required to achieve the result of consistency between the effective taxation of two types of instruments. In the example, both currently taxed and original issue discount bonds (taxed by the old rules) could coexist in financial market equilibrium with no real consequences. If the result for the currently tax bond were correct, then taxing original interest bonds by the old rules would also give the correct result, even though the treatment is not correct, viewed in isolation. Notice that this is not simply another manifestation of the point that inequities tend to be erased through market reactions, at a cost in the form of inefficiency (Bittker, 1980). In this case, the market erases incorrectness at no cost. The opportunities faced by the saver or dissaver would be the same (namely, the after-tax rate of currently taxed interest), regardless of the form of the chosen instrument. So if the current-taxation of ordinary interest were correct, the saver or dissaver would be correctly taxed, regardless of the form of the chosen instrument

The further point is also illustrated by this case, since, with inflation, the basic rule of taxing periodic interest does not produce a measure of accruing real wealth: correctness of the taxation of neither type of instrument is required to eliminate the opportunities for tax arbitrage profit. (Note, however, that, after the market has done its work, with a uniform rate of tax the incorrect rule of taxing nominal interest will produce the economic effect of taxing real income. This is because the market will build the 
taxation of the "inflation premium" in interest rates into the interest rates themselves. (See, for example, Bradford, 1986, pp. 229-230.))

By extension of the same line of reasoning, debt involving any arbitrary cash flow, with arbitrary rules about the timing of inclusion of interest received and deduction of interest paid, could coexist with debt paying periodic interest and taxed according to the usual rules provided the same marginal rate of tax applied to all payers and recipients and inclusion and deduction were simultaneous. I develop this point at greater length below where I look, in particular, at the possibility that such market adjustment would also deal with the cases of contingent return that are the subject of Warren's analysis.

If it is taken for granted that a single-rate system is not a realistic possibility, this analysis will serve simply to highlight the much more serious challenge of designing satisfactory rules for a multiple-rate world. The existence of taxpayers in different marginal rate brackets virtually eliminates the potential to use market adjustment as a substitute for consistent rules to measure returns over time. Something like the yield-tomaturity approach will work for risk-free instruments, but, as Warren's analysis makes clear, that approach will not generalize to cover all the problem cases.

\section{Warren's Analysis}

In his essay, Warren developed two general propositions:

- The present income tax is based on transactions and accords very different treatment to two classes of transaction: those that are held to depend for their resolution on contingencies to be determined in the future ("wait and see transactions"), and those that are held to involve fixed and determinate terms at the outset (taxed on some sort of yield-to-maturity basis). 
- This distinction is not tenable in theory or, increasingly, in practice.

The put-call parity theorem of finance theory provides the key to understanding these propositions. That theorem builds on the fact that buying and holding a share of stock (with market value $S$ ) plus a put on that share with a particular strike price and date (valued in the market at $P$ ), while writing a call on that share with the same strike price and date (valued at $C$ ), produces exactly the same cash flow pattern as results from holding a zero-coupon bond over the period until the strike date. That being the case, the two positions must have the same value in the market. Letting $T$ ("Treasury") stand for the discount bond's value, the theorem says:

$$
S+P-C=T \text {. }
$$

The theorem derives from the fact that the cash-flow consequences of holding the portfolio reflected in the left-hand side are identical under every contingency to holding the Treasury bond reflected in the right-hand side. (I neglect here possible consequences of different rights in the governance of the corporation.) The problem is that the tax treatment of the right-hand side is yield-to-maturity, and of every element of the left-hand side is wait-and-see. In general, the two ways of determining taxable income lead to different results. Specifically, under the current standard rules, the left-hand-side package, the components of which are assumed acquired at the outset of the option period and disposed of or settled for cash on the strike date, is taxed the way original issue discount bonds used to be taxed: capital gain on the difference between purchase price and maturity value (Ferguson, 1994, p. 1003; Warren, 1993, p. 464). The right hand side is taxed (roughly) on accrual. 
It seems almost inevitable that the taxation of financial instruments will involve a blend of yield-to-maturity and wait-and-see elements, which I take to be more or less synonymous with "accrual" and "realization" accounting. Does this inevitably imply the need for nonlinear anti-abuse rules that render the tax system complex and introduce unwanted incentive effects (for example, by disallowing true economic loss deductions)? This is the question to which I now turn.

\section{Time and Marginal Tax Rates}

\section{The World of a Single Marginal Tax Rate}

To develop the analysis I proceed in steps, first looking at the world of certainty, where only time matters. In that world, I first take up the case where all participants in the market confront the same rate of tax. This is the context in which it is most likely that adjustments in the market prices of financial instruments can neutralize potential tax arbitrage profit opportunities.

\section{Symmetry is Sufficient}

For purposes of the rest of this paper I attach particular meanings to the terms "symmetry" and "consistency" as applied to the tax system's treatment of financial instruments. By symmetry I mean the sort of "equal and opposite" treatment of the party and counterparty to a financial instrument that obtains for debt. Shuldiner (1992) uses this term to describe the tax consequences of a transaction if there is "equivalent" treatment of the two sides. I mean here by equivalent treatment that, whenever a transaction has as a consequence a deduction from taxable income for one of the parties to a financial instrument it also has as a consequence an equal and simultaneous inclusion in the taxable 
income of the counterparty. Symmetry involves a party and counterparty. As I use the term henceforth, the concept of consistency supplements symmetry with additional requirements on the tax results from different sets of transactions of a single party. I give more details on this notion of consistency as needed below.

When there is just a single marginal tax rate applicable to all transactors, and the tax treatment applicable to the instrument in question is symmetrical in the sense just defined, then tax effects can be capitalized into market prices of financial instruments. To develop this point, it will be sufficient to consider in detail a two-period world, identified by three time points, 0,1 , and 2 , that we can think of as one year apart.

The basic building blocks are simple one-period ("unit") interest-bearing bonds. A time 0 unit bond sells for 1 at time 0 and pays off $1+r_{01}$ at time 1 . A time 1 unit bond sells for 1 at time 1 and pays off $1+r_{12}$ at time 2 .

Table 1 lays out in general form the cash flows associated with the two possible unit bonds as well as with an arbitrary alternative instrument; $c_{1}$ and $c_{2}$ represent the payoffs from investing $z$ in the alternative instrument at time 0 . For reference, Table 1 also shows the cash flows associated with borrowing in the form of a zero-coupon (discount) bond that will pay 1 at time point 2 and nothing at time point 1 . Its price at time 0 is denoted $z_{02}$, reflecting the fact that it is issued at time 0 and will pay off at time 2 , two periods later. 
Table 1. Cash Flows to Lender Using Various Instruments

\begin{tabular}{|l|c|c|c|}
\hline \multicolumn{1}{|c|}{ Time Point: } & 0 & 1 & 2 \\
\hline Time 0 Unit Bond & -1 & $1+r_{01}$ & \\
\hline Time 1 Unit Bond & & -1 & $1+r_{12}$ \\
\hline Alternative Instrument & $-z$ & $c_{1}$ & $c_{2}$ \\
\hline Discount Bond & $-z_{02}$ & & 1 \\
\hline
\end{tabular}

The two unit bonds fully determine the relative prices of dollars in the three periods. In the absence of taxes, the price of any arbitrary cash flow sequence is determined by eliminating the opportunity for arbitrage profit. This is because any sequence can be reproduced exactly by an appropriate package of purchases and sales of unit bonds. To match the future payoff from the alternative instrument in Table 1, invest

$$
\frac{c_{1}}{\left(1+r_{01}\right)}+\frac{c_{2}}{\left(1+r_{01}\right)\left(1+r_{12}\right)}
$$

in the time 0 unit bond at time 0 . At time 1 the payoff will be

$$
c_{1}+\frac{c_{2}}{\left(1+r_{12}\right)} \text {. }
$$

Extract $c_{1}$ and purchase $\frac{c_{2}}{\left(1+r_{12}\right)}$ units of the time 1 unit bond. At time 2 the payoff will be $c_{2}$

From this description, it seems apparent that the price of the alternative instrument must be given by ( 1 ). At the risk of being tedious, I would emphasize that the underlying mechanism assuring this result is arbitrage. That is, if the going price, $z$, of the alternative instrument differs from the sum needed to be invested at time 0 to reproduce its future cash flows, there will be arbitrage profit to be made. The profit would take the form of a positive cash flow in some period with no offsetting negative cash flow in any period. As 
the description suggests, such a pure surplus could be had by an appropriate sequence of borrowing (selling) and lending (buying) transactions in the unit bonds, coupled with either buying or selling (depending on the direction of the inequality) the alternative instrument.

$$
z=\frac{c_{1}}{\left(1+r_{01}\right)}+\frac{c_{2}}{\left(1+r_{01}\right)\left(1+r_{12}\right)}
$$

When we introduce taxes on unit bonds, the price of the alternative instrument will depend upon the taxable income flows associated with holding it. Table 2 lays out schematically the taxable income associated with the unit bonds as well as an arbitrary sequence of taxable income flows (denoted $t_{i}$ ) that might, hypothetically, be attached to the alternative instrument specified in Table 1. Also shown is the taxable income flow for the zero-coupon bond under the old rules: no tax until realization at time 2, at which point taxable income is the difference between basis and payoff.

Table 2. Taxable Income Flows from Borrower to Lender with Symmetry

\begin{tabular}{|l|c|c|c|}
\hline \multicolumn{1}{|c|}{ Time Point: } & 0 & 1 & 2 \\
\hline Time 0 Unit Bond & & $r_{01}$ & \\
\hline Time 1 Unit Bond & & & $r_{12}$ \\
\hline Alternative Instrument & $t_{0}$ & $t_{1}$ & $t_{2}$ \\
\hline Discount Bond & & & $1-z_{02}$ \\
\hline
\end{tabular}


Readers will be very familiar with the idea that after-tax cash flows are discounted at the after-tax discount rate by taxable investors. This is the essence of the story spelled out in Table 3. In the expressions in the table, the symbol $m_{l}$ stands for the marginal tax rate of the lender, and $m_{b}$ for the marginal tax rate of the borrower. The first row of Table 3 shows the condition on the price, $z^{l}$, of the alternative financial instrument specified in Table 1 at which a lender (the demander of the instrument) would find it an interesting proposition when the applicable tax consequences are as shown in Table 2.

The second row of Table 3 shows the condition on the price, $z^{b}$, of the alternative financial instrument at which a borrower (the supplier of the instrument) would find it an interesting proposition.

A low price for the instrument means a high yield. The equality case of the condition in both rows shows the point of indifference between putting money into the instrument and, instead, putting money into some combination of unit bond purchases and sales. For the lender who is buying the instrument any price is attractive that is below a critical break-even level that depends on the lender's marginal tax rate. For the borrower, who is selling the instrument, the inequality runs in the other direction. An attractive price is one that is higher than a break-even level that depends on the borrower's marginal tax rate. Again, the conditions in Table 3 are based on arbitrage considerations. Thus, for

Table 3. Demand (Lender) and Supply (Borrower) Prices for a Financial Instrument

\begin{tabular}{|c|c|}
\hline $\begin{array}{c}\text { Price at which lender would } \\
\text { be willing to buy the } \\
\text { instrument }\end{array}$ & $z^{l} \leq-m_{l} t_{0}+\frac{c_{1}-m_{l} t_{1}}{\left(1+\left(1-m_{l}\right) r_{01}\right)}+\frac{c_{2}-m_{l} t_{2}}{\left(1+\left(1-m_{l}\right) r_{01}\right)\left(1+\left(1-m_{l}\right) r_{12}\right)}$ \\
\hline $\begin{array}{c}\text { Price at which borrower } \\
\text { would be willing to sell the } \\
\text { instrument }\end{array}$ & $z^{b} \geq-m_{b} t_{0}+\frac{c_{1}-m_{b} t_{1}}{\left(1+\left(1-m_{b}\right) r_{01}\right)}+\frac{c_{2}-m_{b} t_{2}}{\left(1+\left(1-m_{b}\right) r_{01}\right)\left(1+\left(1-m_{b}\right) r_{12}\right)}$ \\
\hline
\end{tabular}


example, if the price is strictly greater than the right hand side value in the second row, there is an arbitrage profit to be made by taxpayer with marginal tax rate $m_{b}$, by borrowing in the form of selling the instrument for a relatively high price, using the proceeds to lend in the unit bond market, to finance the future payoff on the alternative instrument (taking into account the associated tax consequences).

If $m$ is the single applicable marginal tax rate, there will be exactly one value of the instrument satisfying both conditions specified in Table 3. The opportunity for arbitrage profit for both borrowers and lenders is eliminated simultaneously by the price given in expression ( 2 ), which corresponds to ( 1 ) with taxes taken into account.

$$
z=-m t_{0}+\frac{c_{1}-m t_{1}}{\left(1+(1-m) r_{01}\right)}+\frac{c_{2}-m t_{2}}{\left(1+(1-m) r_{01}\right)\left(1+(1-m) r_{12}\right)}
$$

The fact that there is a single tax rate implies that the discount factors (the factors multiplying the cash flows) on the right hand side of ( 2 ) are the same for everyone, and the fact of symmetry in the taxable income flows means that the amount added to or subtracted from the after-tax cash flows as a result of the tax is the same for everyone. Any positive amount of tax that has to be paid by the lender will be reflected in a lower price that the lender would be willing to pay for the instrument, that is, a lower amount that can be realized by the borrower, who is exactly compensated by the corresponding deductions.

\section{What If Demand and Supply Prices Differ?}

With different marginal tax rates, the critical values of the demand and supply prices, the prices that would render demanders and suppliers indifferent between the alternative instrument and the package of unit bonds that reproduces the future cash flows, 
will generally differ. There are two possibilities: First, the maximum price the lender would be willing to pay for the instrument could be below the minimum price the borrower would be willing to accept. In this case, the transaction in question would not be observed. The same effective transaction would be carried out using unit bonds.

The second possibility is that the maximum price the lender would be willing to pay for the instrument exceeds the minimum price the borrower would accept. Here we would say that capital market equilibrium does not exist in the model world. Translated into application, it means that there would be no natural limit on the tax arbitrage profit to be made at a price somewhere between the two limits. The lender would sell the time 0 unit bonds to buy the alternative instrument and the borrower would buy time 0 unit bonds with the proceeds of selling the alternative instrument.

These two possibilities are not independent. If there is a transaction that would not take place between a borrower in one tax bracket and a lender in the other (because it is unattractive to both sides), the reverse transaction will provide an opportunity for tax arbitrage profit. 
Price adjustments cannot eliminate this profit potential. Either the marginal tax rates must be equated, or linearity of the tax rules must be sacrificed (for example, incorporating limits on the allowable loss that can be claimed by a taxpayer) ${ }^{7}$

As the algebra suggests, if there is any potential for arbitrage profit, the absolute amount of profit is proportional to the scale of the transactions. Since the pure arbitrage transaction involves no actual cash changing hands (except with the tax collector) there is no natural limit. As a practical matter, however, the transactions are not costless, so the quantitative importance of the potential for arbitrage profit depends sensitively upon the degree of difference in marginal tax rates and on the interest rate.

\section{The Case of a Zero-Coupon Bond}

The taxation of cash-basis issuers and holders of a zero-coupon bond under the old rules provides a convenient illustration of these ideas. Under this rule for taxable income, the market-clearing price of the zero-coupon bond implied by ( 2 ) is ( 3 )

$$
z_{02}=\frac{1-m\left(1-z_{02}\right)}{\left(1+(1-m) r_{01}\right)\left(1+(1-m) r_{12}\right)}
$$

Some algebra translates condition ( 3 ) into ( 4 ), which should have a familiar look. The discount factor on the right hand side is modified from the no-tax case by terms

${ }^{7}$ In a graduated rate system, the marginal tax rate can adjust endogenously. So, for example, if high bracket taxpayers could deduct interest on borrowing to hold tax exempts and low bracket taxpayers could costlessly go short tax exempts, tax arbitrage would lead everyone to end up in the same marginal rate bracket. Someone whose marginal tax rate was below this common level would lend on a taxable basis and borrow tax exempt by going short. The result would be an arbitrage gain, a higher taxable income, and a higher marginal tax rate. The opportunity for arbitrage profit would persist until marginal tax rates were all equal. Note that a limit on allowable loss deductions can also be viewed as making the marginal tax rate endogenous, since a taxpayer up against the limit faces a 
that incorporate the advantage to the lender of the deferral of tax, from time 1 to time 2 , on the implicit yield between time 0 and time 1 . If the marginal tax rate is zero, the right hand side reduces, as expected, to the no-tax expression. A positive marginal tax rate raises the equilibrium price of the instrument, the amount the lender would be willing to give and the borrower require to be paid for the future cash and taxable income flows. (It is not clear from the derivation, but is the case, that the tax rate in question in this example is the one that applies at time 1.)

$$
z_{02}=\frac{1}{\left(1+r_{01}\right)\left(1+r_{12}\left(\frac{1+(1-m) r_{01}}{1+r_{01}}\right)\right)}
$$

\section{Under General Conditions, Symmetry is Necessary}

As has been demonstrated, with a single tax rate, symmetry of the rule determining the income of party and counterparty of a financial instrument is sufficient for any disparity from the treatment of the unit bonds to be completely absorbed in the price of the instrument. There is no need to provide special rules to limit tax arbitrage profit. (Note that this statement requires that there really be just one rate. This condition would be violated by, for example, the presence of tax exempt participants in a market where taxable persons or entities all have some positive marginal rate.)

A natural question is whether symmetry is also necessary. That is, would a rule that violated symmetry necessarily result in an unlimited opportunity for tax arbitrage profit? The answer is yes if we confine our attention to the case in which the sum of the deductions from taxable income by one party over the life of the instrument equals the sum

marginal tax rate of zero on further losses of the type subject to the limit. For further 
of inclusions in taxable income by the counterparty. (Two additional conditions are taken for granted: interest rates and the single marginal tax rate are positive.)

Here is the argument. Suppose the tax rules do not have the symmetry property with respect to some particular position. For example, let the offending case involve a deduction for the "borrower" side of the position (I use the term just to identify one of the counterparties), that occurs before the inclusion in the income of the lender. This would describe the old treatment of the discount bond issued by an accrual taxpayer to a cash taxpayer in the same rate bracket. To be concrete, suppose that the borrower in a unit position of this financial instrument gets to deduct $\$ 100$ at some point, but that the lender does not have to include the $\$ 100$ until two years later. Now suppose a person takes both sides of this financial instrument, being both borrower and lender. Then there is no net cash flow involved apart from taxes. But by virtue of being the borrower, the taxpayer gets a deduction of $\$ 100$ at some point, which is offset by an inclusion of the same amount, two years later. If there is a positive after-tax interest rate, this change in the timing of tax liabilities is valuable. By further transactions in the unit bonds, the taxpayer could arrange for a cash flow sequence that is positive at some time point and never negative.

There is no way to eliminate this tax advantage through adjustment in the price at which the position is exchanged, since it results from holding simultaneously opposite sides of the same instrument.

development of the role of endogenous adjustment in marginal rates, see Bradford (1980). 


\section{Current Realization Approach to Capital Gains Taxation Fails the Symmetry Test}

The discussion of the zero-coupon bond, showing that capital markets could incorporate taxation at maturity on a capital gain basis, assumed that both issuer and purchaser of the instrument held the instrument to maturity. Barring limits on capital losses, however, it will generally be advantageous for one side or the other of this transaction to accelerate the realization of a loss at time 1 . The tax treatment of the position held to maturity, while formally correct, is therefore of limited relevance. The question is, whether the tax that results from optimized realization behavior can be incorporated into the market price (always given a single applicable marginal tax rate).

Table 4. Cash and Taxable Income Flows to Borrower (Taxpayer Option to Realize)

\begin{tabular}{|l|l|c|c|c|}
\hline \multicolumn{2}{|c|}{ Time Point: } & 0 & 1 & 2 \\
\hline $\begin{array}{l}\text { Discount Bond if Paid } \\
\text { Off at Maturity }\end{array}$ & Cash & $z_{02}$ & & -1 \\
\cline { 2 - 5 } & Taxable Income & & & $-\left(1-z_{02}\right)$ \\
\hline $\begin{array}{l}\text { Discount Bond if } \\
\text { Transferred to } \\
\text { Another Person at } \\
\text { Time Point 1 }\end{array}$ & $\begin{array}{l}\text { Cash (aggregate to } \\
\text { borrower's side) }\end{array}$ & $z_{02}$ & & -1 \\
\cline { 2 - 5 } & $\begin{array}{l}\text { Taxable Income } \\
\text { (aggregate to } \\
\text { borrower's side) }\end{array}$ & & $-\left(z_{12}-z_{02}\right)$ & $-\left(1-z_{12}\right)$ \\
\hline
\end{tabular}

Examination of the sequence of transactions in Table 4 establishes that the taxable income flows that result when taxpayers advantageously time their realizations fail the test of symmetry. It is possible to establish zero-market value positions that shift tax liability toward the future. Table 4 lays out the taxable income flow to the borrower under two scenarios. In the first, the original borrower pays off the loan at maturity. In the second 
the original borrower pays someone else an amount $z_{12}$, the price of the discount bond as of time 1 , to take over the obligation. There is no net cash flow in the aggregate to the borrower's side at time 1, since the original borrower's outflow is matched by the inflow of the person taking over the obligation. But there is an increase in the original borrower's liabilities for tax purposes amounting to $z_{12}-z_{02}$, which can be claimed as a deduction. The remaining unrealized loss to the borrower side of the financial instrument appears as the deduction, $1-z_{12}$, at time 2 . If the lender waits to realize gain until maturity, the taxable income flows are asymmetric, and the net effect, in the aggregate, is to accelerate the deduction side, relative to the inclusion side. Table 5 and Table 6 spell out the details.

Table 5 describes an arbitrage sequence in that the transactions are organized to produce a net cash flow of zero at every time point except time 1. The "bottom line" in

Table 5. Details of Discount Bond Issuer's Tax Arbitrage Transactions

\begin{tabular}{|r|c|c|}
\hline Time Point: & \multicolumn{1}{|c|}{0} & \multicolumn{1}{|c|}{1} \\
\hline Transaction: & $\begin{array}{l}\text { Issue } 1 / z_{02} \text { discount } \\
\text { bonds for } \$ 1 . \\
\text { Buy unit bond. }\end{array}$ & $\begin{array}{l}\text { Receive principal plus interest on the } \\
\text { unit bond. } \\
\text { Pay someone to take over the } \\
\text { discount bonds, realizing a loss. } \\
\text { Pay any taxes due. }\end{array}$ \\
\hline Details of transactions: & -1 & $\frac{-1 / z_{02}}{1+r_{12}}$ \\
\hline Time 0 Unit Bond & 1 & $-m r_{01}+m\left(\frac{1 / z_{02}}{1+r_{12}}-1\right)$ \\
\hline Discount Bond & 0 & $1+r_{01}-\frac{1 / z_{02}}{1+r_{12}}-m\left(r_{01}+1-\frac{1 / z_{02}}{1+r_{12}}\right)$ \\
\hline Tax & 0 &
\end{tabular}


the table shows just such a sequence. There is an arbitrage profit if the one non-zero result, shown in the lower right hand cell of the table, is positive. To bring about the required pattern, the issuer of $1 / z_{02}$ units of the discount bond uses the $\$ 1$ proceeds to buy a time 0 unit bond. The third column of Table 5 shows the cash flow at time 1, when the discount bond issuer unwinds the pair of positions. The time 0 bond pays off $\left(1+r_{01}\right)$. The discount bond is equivalent to a quantity of time 1 unit bonds, since there is no tax advantage to the holder looking ahead from that point. So the $1 / z_{02}$ units must be worth the payoff amount at time $2,1 / z_{02}$, discounted at the time 1 unit bond rate, $r_{12}$. The issuer of the discount bond will thus have to pay someone that amount to take over the instrument, giving rise to the cash outflow $\frac{1 / z_{02}}{1+r_{12}}$. There are, in addition, cash flows owing to the tax consequences of all this: $-m r_{01}$ (an outflow) due to the interest received, and $m\left(\frac{1 / z_{02}}{1+r_{12}}-1\right)$ (an inflow) due to the fact that the amount paid to buy out of the discount bond obligation exceeds the amount received on its issue. The net proceeds are shown in the lower right-hand cell of Table 5 ; the no profit condition for the issuer, expressed algebraically by ( 5 ), is that this amount be less than or equal to zero.

$$
1+r_{01}-\frac{1 / z_{02}}{1+r_{12}}-m\left(r_{01}+1-\frac{1 / z_{02}}{1+r_{12}}\right) \leq 0
$$

Condition ( 5 ) simplifies to ( 6 )

$$
z_{02} \leq \frac{1}{\left(1+r_{12}\right)\left(1+r_{01}\right)} \equiv a
$$

Table 6 depicts the other side of the market, showing the result of financing the holding to maturity of $\$ 1$ worth of the discount bond by a sequence of borrowings in the 
form of unit bonds. Note that there is a fourth column, showing the cash flows at time 2 . The transactions are designed to produce a net cash flow of 0 except at time 2 . The lower right-hand cell of Table 6 contains the net result at time 2 , from which we see that the no profit condition for the person who lends in the form of a discount bond (the buyer of the instrument) is given by ( 7 ),

$$
-\left(1+(1-m) r_{01}\right)\left(1+r_{12}\right)+\frac{1}{z_{02}}-m\left(\left(\frac{1}{z_{02}}-1\right)-r_{12}\left(1+(1-m) r_{01}\right)\right) \leq 0
$$

which simplifies to ( 8 ).

$$
z_{02} \geq \frac{1}{\left(1+r_{01}\right)\left(1+r_{12}\left(\frac{1+(1-m) r_{01}}{1+r_{01}}\right)\right)} \equiv b
$$

Taking ( 6 ) and ( 8 ) together, if the marginal tax rate and the first period interest rate are positive, i.e., $m>0$ and $r_{01}>0$, then the critical price, $b$, for the lender is greater than the critical price, $a$, for the borrower. A price for the discount bond that simultaneously eliminates opportunities for arbitrage profit by borrower and lender thus must satisfy the condition that it is less than itself, $z_{02}<z_{02}$. This is impossible; no such price exists. 
Table 6. Discount Bond Lender's Tax Arbitrage Transactions

(Taxpayer Option to Realize)

\begin{tabular}{|c|c|c|c|}
\hline Time Point: & 0 & 1 & 2 \\
\hline Transaction: & $\begin{array}{l}\text { Buy } 1 / z_{02} \\
\text { discount } \\
\text { bonds for } \\
\$ 1 \text {. } \\
\text { Sell time } 0 \\
\text { unit bond } \\
\text { (borrow). }\end{array}$ & $\begin{array}{l}\text { Pay principal plus } \\
\text { interest on the unit } \\
\text { bond. } \\
\text { Collect tax savings } \\
\text { from interest } \\
\text { deducted. } \\
\text { Sell time } 1 \text { unit } \\
\text { bonds to cover the } \\
\text { difference. }\end{array}$ & $\begin{array}{l}\text { Collect } 1 / z_{02} \text { on the discount } \\
\text { bonds. } \\
\text { Pay principal plus interest on the } \\
\text { time } 1 \text { unit bonds. } \\
\text { Pay any taxes due. }\end{array}$ \\
\hline \multicolumn{4}{|l|}{ Details of cash flows: } \\
\hline Time 0 Unit Bond & 1 & $-\left(1+r_{01}\right)$ & \\
\hline Time 1 Unit Bond & & $\left(1+(1-m) r_{01}\right)$ & $-\left(1+(1-m) r_{01}\right)\left(1+r_{12}\right)$ \\
\hline Discount Bond & -1 & & $1 / z_{02}$ \\
\hline $\operatorname{Tax}$ & 0 & $m r_{0 I}$ & $-m\left(\left(\frac{1}{z_{02}}-1\right)-r_{12}\left(1+(1-m) r_{01}\right)\right.$ \\
\hline Net & 0 & 0 & $\begin{array}{l}-\left(1+(1-m) r_{01}\right)\left(1+r_{12}\right)+\frac{1}{z_{02}}- \\
m\left(\left(\frac{1}{z_{02}}-1\right)-r_{12}\left(1+(1-m) r_{01}\right)\right)\end{array}$ \\
\hline
\end{tabular}

\section{Possible Fixes for Capital Gains}

The stark conclusion is that, even if there is just one marginal tax rate, some nonlinearity (such as the ceiling on the deductibility of losses) is required to limit tax arbitrage profit when income is based on the present realization conventions. Note that this particular conclusion has nothing to do with "cherry picking" or other risk-related phenomena, but rather turns on timing alone: The party and counterparty can choose 
different realization paths, to their mutual advantage. Some other approach, satisfying the symmetry requirement, would be required, of which the following four are examples.

\section{Mark to Market}

Under a mark-to-market rule, the holder of an instrument would recognize gain or loss each period by including in income the difference in the instrument's market value and its basis at the end of the period. Recognized gain would be added to basis (and loss deducted from basis). Cash payments received during the period would be subtracted from basis. If the issuer of such an instrument were treated in the same way, except that cash payments paid during the year were added to basis, any time holding one side of the position resulted in a loss, holding the other side would result in a gain of the same amount, thereby satisfying the symmetry property.

\section{Ignore Intermediate Transactions}

Another approach would be to provide that a sale of an instrument such as the illustrative zero-coupon bond would have no tax consequences. Basis would go along with the instrument. The purchaser of the instrument at time 1 would thus obtain with the future cash flow the future taxable income flow that would otherwise have gone to the initial holder. In this way, the symmetry of the tax treatment would be assured.

As a result, the market could incorporate any apparent mismeasurement of income into the prices of financial instruments, provided that everyone in the market faced the same tax rate. The future tax consequences for the ultimate holder of the instrument at maturity would be discounted into the price obtained at intermediate points. In our example, it is readily shown that the market-clearing price at issue in this case would be given by ( 4 ), and the price at time 1 by ( 9 ). 


$$
z_{12}=\frac{\left(1+(1-m) r_{01}\right)}{\left(1+r_{01}\right)\left(1+r_{12}\left(\frac{1+(1-m) r_{01}}{1+r_{01}}\right)\right)}
$$

\section{Impute Interest Currently}

Another possibility would be to impute interest to the holder of a financial instrument, providing as well an addition to basis. ${ }^{8}$ (The issuer would obtain an imputed deduction and corresponding basis adjustment.) Cash payment from borrower to lender, whether representing "interest" or "principal," would give rise to a deduction from basis of the lender and a corresponding adjustment for the borrower. It can be shown that under these rules the price a taxpayer would be willing to pay for the discount bond would be the same as in the no-tax world. This implies that the price would be independent of the applicable tax rate (by contrast with the previous example)

This is very close to the present treatment of a discount bond. Present treatment involves calculating a yield to maturity and imputing annual interest income to the lender (and allowing a deduction to the borrower) of the product of that rate and the adjusted basis of the instrument, which is increased by the amount of the imputed interest. The main difference from the suggested alternative is that the adjustment required to eliminate the potential for arbitrage profit from selective timing of capital gain and loss on the instrument is the current period's market rate, not a yield to maturity.

The yield to maturity of a financial instrument is that uniform rate of period-byperiod interest that equates the market value of the instrument to the discounted value of its future cash flows. If the actual, known, future period-by-period interest rates vary in

\footnotetext{
8 This is the approach suggested by Cunningham and Schenk (1992).
} 
the risk-free context assumed in this section, then the yield-to-maturity of an instrument with any arbitrary cash-flow profile will be a kind of average of them. If, on the other hand, the actual, known, future period-by-period interest rates are the same, then the yield to maturity of an instrument will equal that common value. It is only in this case that the present yield-to-maturity method of assigning interest income and deductions forecloses profit from tax arbitrage using unit bonds. When there is variation in the one-period interest rate, the yield-to-maturity approach to imputation results in a difference between an instrument's basis and its market value, opening up the possibility for tax arbitrage profit. ${ }^{9}$ (There is an additional element involved in the term structure of interest rates in practice: future unit bond rates are not known, so that the price of a future dollar incorporates a bet on future interest rates, as well as purely intertemporal value. I develop this point below.)

In the world of perfect certainty, imputation of interest should result in exact equality between the market value of an instrument and its adjusted basis. This precise equality would fail, in general, under the yield-to-maturity approach. As a practical matter, however, by narrowing the difference between basis and market value, the yieldto-maturity imputation presumably greatly narrows the potential for profit, that is, increases the likelihood that transactions costs would swamp the gain, even if limitation on the deductibility of capital losses did not address the problem in another way.

${ }^{9}$ See Bankman and Klein (1989), Sims (1992). 


\section{Impute Interest on Realization}

Another possibility would be to impute interest on realization. That is, at the time the instrument is sold, the taxable income would be based, in effect, on the assumption that the proceeds of the sale were the result of a sequence of investments in unit bonds (at each intermediate point reinvesting the proceeds from the previous point's investment) from the time of acquisition to the sale date. The period-by-period interest payments thus imputed to the instrument at the time of sale would be allocated to the intervening tax years. Interest would be charged on any taxes that would have been due, with everything settled up at the time of sale. ${ }^{10}$ (The tax on an instrument held to maturity would be the same as that on one sold at that time for the payoff amount. Cash payments received during the holding period would be treated as sales proceeds on a position held since the acquisition date of the underlying instrument.)

The only observed facts about the transaction used in this approach are the sale price of the instrument and its acquisition date. The amount of money that changed hands at the time of acquisition does not enter the calculation; the concept of basis is not invoked.

The symmetrical treatment would apply to the issuer of the instrument, who would obtain, in effect, a deferred interest deduction. Intermediate cash flows would be treated as realizations, dated from the time of acquisition.

10 This is the Auerbach (1991) method. 
Table 7 lays out the details of this approach in the two-period context. Note that the net-of-tax payoff on the discount bond at time 2 (the lower right-hand cell of Table 7) simplifies to ( 10 ).

$$
1-\frac{m\left(\left(1+r_{01}\right)-m r_{01}\right) r_{12}}{\left(1+r_{01}\right)\left(1+r_{12}\right)}-\frac{m r_{01}\left(1+r_{12}\right)}{\left(1+r_{01}\right)\left(1+r_{12}\right)}=\frac{\left(1+(1-m) r_{01}\right)\left(1+(1-m) r_{12}\right)}{\left(1+r_{01}\right)\left(1+r_{12}\right)}
$$

The market equilibrium price of the instrument is determined by discounting the after-tax cash flows at the after-tax interest rates. As shown in ( 11 ), as in the case of imputing interest currently to basis (and adjusting basis accordingly), under the suggested tax rules, the price is independent of the investor's tax rate, being simply the discounted (at the before-tax market interest rates) value of before-tax flows.

$$
z_{01}=\frac{\frac{\left(1+(1-m) r_{01}\right)\left(1+(1-m) r_{12}\right)}{\left(1+r_{01}\right)\left(1+r_{12}\right)}}{\left(1+(1-m) r_{01}\right)\left(1+(1-m) r_{12}\right)}=\frac{1}{\left(1+r_{01}\right)\left(1+r_{12}\right)}
$$

Although I have not spelled it out in detail, it is the case that this rule results in tax effects' being incorporated to asset prices even though it does not satisfy the property of symmetry (since either party to the instrument has the option to sell at time 1). It might be thought that this fact contradicts the conclusion that symmetry is necessary, as well as sufficient, for tax effects to be fully incorporated to market prices of instruments. Necessity, however, was shown to obtain for rules that result in equality between the sum of inclusions in and deductions from income for the party and counterparty to the instrument. The interest-imputation-on-realization rule may not satisfy this condition, and would not do so in the case in which one party chose to realize at time 1 , whereas the counterparty realized at time 2 . This rule satisfies, instead, the weaker symmetry 
Table 7. Imputing Interest at Maturity to Discount Bond Lender

\begin{tabular}{|c|c|c|c|}
\hline Time Point: & 0 & 1 & 2 \\
\hline Transaction: & $\begin{array}{l}\text { Buy } 1 \\
\text { discount } \\
\text { bond for } z_{02} \text {. }\end{array}$ & & $\begin{array}{l}\text { Collect } 1 \text { on the discount } \\
\text { bond. } \\
\text { Pay any taxes due. }\end{array}$ \\
\hline $\begin{array}{r}\text { Valuation Implicit in Tax } \\
\text { Calculation at Time } 2\end{array}$ & & $\frac{1}{\left(1+r_{01}\right)\left(1+r_{12}\right)}$ & $\frac{\left(1+r_{01}\right)-m r_{01}}{\left(1+r_{01}\right)\left(1+r_{12}\right)}$ \\
\hline $\begin{array}{r}\text { Implicit Interest in Tax } \\
\text { Calculation at Time } 2\end{array}$ & & $\frac{r_{01}}{\left(1+r_{01}\right)\left(1+r_{12}\right)}$ & $\frac{\left(\left(1+r_{01}\right)-m r_{01}\right) r_{12}}{\left(1+r_{01}\right)\left(1+r_{12}\right)}$ \\
\hline $\begin{array}{r}\text { Implicit Tax on Implicit } \\
\text { Interest in Tax Calculation } \\
\text { at Time } 2\end{array}$ & & $\frac{m r_{01}}{\left(1+r_{01}\right)\left(1+r_{12}\right)}$ & \\
\hline Tax on Implicit Interest & & & $\frac{m\left(\left(1+r_{01}\right)-m r_{01}\right) r_{12}}{\left(1+r_{01}\right)\left(1+r_{12}\right)}$ \\
\hline $\begin{array}{r}\text { Interest on Deferred } \\
\text { Implicit Tax }\end{array}$ & & & $\frac{m r_{01}\left(1+r_{12}\right)}{\left(1+r_{01}\right)\left(1+r_{12}\right)}$ \\
\hline After-Tax Cash Flow & $-z_{02}$ & & $\begin{array}{c}1-\frac{m\left(\left(1+r_{01}\right)-m r_{01}\right) r_{12}}{\left(1+r_{01}\right)\left(1+r_{12}\right)} \\
-\frac{m r_{01}\left(1+r_{12}\right)}{\left(1+r_{01}\right)\left(1+r_{12}\right)}\end{array}$ \\
\hline
\end{tabular}

condition, that the discounted sum of taxable inclusions equal the discounted sum of deductions from the tax base, which is sufficient as well as necessary for the result.

Correctness in the Treatment of Time

With symmetry, or with its present value equivalent, and a single rate of tax, tax arbitrage profit will be eliminated in financial market equilibrium, where the taxation of the unit bonds -- the taxation of ordinary, one-period interest -- is taken as the fixed element 
of the system. As I have already stressed, this fixed element does not give the correct measure if by "correct" is meant real (inflation-corrected) income. ${ }^{11}$

Getting to a correct measure would require adjusting the nominal interest receipts and payments to extract the inflation premium. ${ }^{12}$ A relatively simple procedure for doing so would be to generalize the imputation of interest to basis for all assets, including the ordinary one-period bonds that are the foundation stones of the income measurement system. Income for the year would be the product of adjusted basis and whatever is determined to be the inflation-adjusted interest rate. The annual adjustment to basis would include, in addition to the usual increase for imputed interest and decrease for any cash received, a percentage increase equal to the change in the price level during the period. (Basis adjustment for cash flows between the beginning and end points of the year would require some appropriate approximation for price-level change during the year.)

Given that interest imputation is required for all but the fundamental one-period instruments in any case, it would thus be conceptually fairly simple to implement an inflation-corrected tax. If the analysis were extended to take into account, for example, real investment, inflation correction would be an important consideration (since tax arbitrage forces come into play in that connection as well).

In the world of a single marginal rate, taxing nominal interest involves an incorrect income measure, but need not produce an incorrect result. That is because the market could take into account both the real and nominal elements of the transaction. For

11 I have elsewhere (1996) described taxation of nominal interest as giving rise to a "nominal economic income" tax.

12 For discussion and references to the literature, see Bradford (1986). 
example, the nominal interest rate should vary by $1 /(1$-tax rate) per percentage point of anticipated, steady inflation. With a 33 percent marginal rate, an interest rate of 3 percent with no inflation and interest rate of 18 percent with inflation of 10 percent per year would offer exactly the real same after-tax borrowing and lending terms. (18 percent less 33 percent of 18 percent in tax gives a 12 percent after-tax nominal return. Subtracting the 10 percent inflation, leaves a 2 percent real after-tax return, the same as in the no-inflation case.) With multiple tax rates, however, it is impossible for the financial markets to produce an adjustment that works for all taxpayers. Then incorrect income-measurement produces "incorrect" real results, as well. ${ }^{13}$

\section{Multiple Tax Rates and the Consistency Requirement}

When we leave behind the world of the single tax rate, the constraints on the rules necessary to permit the elimination of tax arbitrage profit in a linear income measurement system become more stringent. Symmetry is no longer sufficient. Rather consistency of income measurement is both sufficient and, under conditions, necessary.

Shuldiner defines consistency as the "equivalent treatment by a single taxpayer of two or more individual transactions making up parts of a larger overall transaction." (1992, p. 782) What $I$ have in mind is similar. I specify consistency as requiring that a given sequence of net cash flows give rise to the same taxable income flows for all taxpayers, regardless of how that cash flow is composed out of one or more financial instruments. Because it is more specific about the meaning of "equivalent treatment" and

\footnotetext{
13 The Comprehensive Income Tax proposal described in the U.S. Treasury's Blueprints
} for Basic Tax Reform erred in relying on financial markets to produce an automatic 
refers to all taxpayers, it is more restrictive than Shuldiner's concept. As I use the term here, it is also more restrictive in adding symmetry, which relates to the tax consequences to the two parties to a financial instrument. Consistency as I use the term here implies symmetry under my definition, but not vice versa. Assuming that he means to imply the treatment is universally applicable to all taxpayers, it appears to be close to Strnad's usage, at least for the case of certainty: "A tax system is consistent if and only if every cash flow pattern has a unique tax treatment." (1994, p. 573)

The "old" treatment of the (cash-basis) issuer and holder of an OID bond is an example of measurement that is symmetrical but not consistent with the treatment of the equivalent sequence of one-period loans. Yield-to-maturity treatment of an OID bond gives an example of an effort to achieve consistency. The ideas are (a) that the taxpayer who has a cash flow from the date of issue of the zero-coupon discount bond to its maturity should have the same set of inclusions in taxable income, regardless of whether the cash flow is the result of holding the zero-coupon discount bond or a series of oneperiod instruments and (b) whenever one party has an inclusion in income, the counterparty has a deduction (subject to any limitations that would apply to a borrower making ordinary periodic interest payments).

The sufficiency of consistency so defined to eliminate the potential for relevant tax arbitrage profit using financial instruments follows almost by definition. Tax arbitrage is effected by taking a position in two or more financial instruments so as to produce a zero net cash flow each period on a before-tax basis, but a valuable flow of taxable income. (In

adjustment of interest income for inflation, an error on which I commented in the Preface 
the usual case, a flow of taxable income is valuable if it has a positive net present value at after-tax discount rates; in other words, when it gives rise to an acceleration of deductions or deferral of taxable income.) If income measurement is consistent, a combination of instruments that gives rise to a zero net cash flow each period must bring with it the same sequence of taxable income flows as any other such combination of instruments. But it cannot be the case that holding no financial instrument (and therefore a zero net cash flow each period) results in a favorable flow of taxable income.

The more interesting proposition is that consistency is necessary under reasonable conditions. These conditions are the same ones as applied in the single-rate case: for rules that imply the sum of inclusions and the sum of deductions on the two sides of a financial instrument are the same, consistency is necessary if there is always more than one tax rate in the population of taxpayers and if interest rates are positive.

The argument is very close to the one given above for the necessity of symmetry. Start with the taxable income flows that are associated with the unit bonds. Refer to as "the" after-tax discount rates the implied net of tax rates of return from unit (one-period) bonds. If the tax rules do not have the consistency property then there must be some instrument such that the sequence of one-period bond transactions that duplicates its cash flow produces a different sequence of taxable income flows. Suppose the price of this other instrument adjusts, along the lines discussed earlier, so as to render the two positions indifferent for taxpayers with a particular tax rate. (If the price does not so adjust, there is an opportunity for tax arbitrage profit for those taxpayers.) Then the discounted sum of 
inclusions in the tax base of the "lender" side of the other instrument, using the after-tax discount rates, must be the same as the discounted sum of deductions from the tax base of the "borrower," using the same after-tax discount rates. At a different tax rate, the aftertax discount rates will differ. But two different sequences of cash flows that have the same discounted value at one set of discount rates will have different discounted values at another set of discount rates. It is impossible to eliminate the potential for arbitrage profit without giving up the linearity of the tax (or setting all marginal tax rates equal).

\section{OID Rules Illustrate the (Strictly Speaking. Unsuccessful) Quest for Consistency}

As discussed above in connection with the analysis of the single-tax rate system, the present rules for inclusion of interest on an original issue discount bond (impute interest at the implied yield to maturity) fail the symmetry test when combined with the option to realize gain or loss. If we restrict our attention to OID bonds held to maturity by both counterparties, there is symmetry but still, in general, a failure of consistency. Except when the one-period interest rates are all the same, the sequence of transactions in unit bonds that reproduces the OID cash flows will generate a different path of taxable income flows. Whereas this difference in tax results can be built into the price of the instrument when there is a single tax rate, when there are multiple tax rates, there will always be an opening for tax arbitrage profit through transactions between a pair of taxpayers with different marginal rates. ${ }^{14}$ (To be sure, the opening may be very small. Transactions costs will typically swamp it.)

\footnotetext{
14 See, again, Bankman and Klein (1989), Sims (1992)
} 
Present Realization Approach to Capital Gains Taxation Fails the Consistency Test

Since the present realization regime for capital gains fails the symmetry test, $a$ fortiori it fails the consistency test. Some of the techniques, discussed in the single-rate context, that produce symmetric treatment require modification to produce consistency.

\section{Mark to Market}

Since mark to market taxation produces exactly the same path of taxable income as results from the duplicating sequence of unit bond transactions, it satisfies consistency.

\section{Ignore Intermediate Transactions}

Ignoring intermediate transactions in an instrument between issue and maturity (with basis carried over), which guaranteed symmetry, would not generally produce consistency. This method assures that the path of deductions by the "borrower" side of an instrument is equal and opposite to the path of inclusions by the "lender" side, regardless of intervening sales by either side. The problem, however, is that this symmetric result is not the same as the path of taxable income associated with the duplicating sequence of unit bond transactions.

\section{Impute Interest Currently}

The technique of imputing interest currently would produce consistency. It is important that the interest imputed be identical to that obtaining on the unit bonds, as this is how the potential for tax arbitrage is eliminated. This could be effected by taxing the unit bonds themselves on an imputed-interest basis, in which case the applicable rate could be chosen as a matter of policy (for example, to equal the inflation-corrected rate). 


\section{Impute Interest on Realization}

As we noted, the technique of imputing interest on realization fails the strict symmetry test, but satisfies an appropriate generalization in the case of a single-rate system. Roughly the same conclusion applies in the multiple rate system to a modified specification of this approach. To achieve the effect of consistency, the look-back that treats the seller of an instrument as having accrued interest at the market rate would have to apply the seller's marginal tax rates (both for the implied periodic taxes and for the effect of any acceleration or deferral of tax payments). Then the discounted value of the taxable income flows (at the after-tax discount rates applicable for the taxpayer in question) will be the same as that of the duplicating unit bond transactions. This equality is the generalization of the consistency notion that is necessary to eliminate the potential for relevant arbitrage profit with multiple marginal tax rates.

Using, instead, a single marginal tax rate, rather than the seller's actual marginal tax rates through time, to infer the factor to apply to the proceeds of sale would fail the consistency test.

\section{The Taxation of Risky Instruments}

Pure Risk Effects: Timeless Gambles

Perhaps because uncertainty is inextricably bound up with sequence (before and after its resolution), we tend to think of risk and intertemporal return together. Thus, for example, if I enter into a forward contract to purchase some asset at a specified price on a specified date, in the typical situation the price is so chosen that the value of my position at the outset is zero. Immediately thereafter, however, as information about the future begins to unfold, my position acquires value. Whether the value is positive or negative 
depends upon whether the new information implies the future price is more likely to be higher or lower than anticipated earlier. If the former, my position acquires a positive value. If the latter, my position acquires a negative value. The value of the position of the counterparty to my contract moves in exactly the same amount but in the opposite direction. These effects occur with the passage of time, but time is not of the essence in the changing values. On the contrary, if all that happens is the passage of time, and no new information develops, the value of the position will not change at all.

Taxing pure bets between a party and a counterparty, involving sequence (before and after the resolution of uncertainty) but not the passage of time, is less problematical than the taxation of transactions involving time. The striking fact is that, provided the same tax rate applies to the gains and losses from a risky position, the tax rate itself is of no fundamental importance. The reason is simple: the tax has the effect of reducing the scale of the bet but not the relative payoffs under the various relevant contingencies.

Since transactors have the option of varying the scale of their bets without recourse to the tax system, taxation does not affect the set of possible bilateral bets at all.

To illustrate, by analogy with the choice between a series of one-period loans and a zero-coupon discount bond, suppose there were two kinds of bets, taxable and not, with the choice left up to the transactors. For example, suppose gains and losses from flipping pennies are taxable if the bet is governed by a contract written in red ink, but not if it is governed by a contract written in green ink. The green ink deals get the wrong result from the point of view of proper income accounting. But one cannot produce tax arbitrage profit consequences. 
The analogy to the discount case would involve something like my writing a red contract betting on heads and a green contract betting on tails for the same coin flip (thereby eliminating any actual risk), and the counterparty doing the opposite. It is true that this would convert an apparently riskless situation for me into a genuine gamble, because I will either pay tax or collect a refund, depending on the coin flip. My counterparty on the red contract will experience the opposite taxable income outcomes. But there is no opportunity for arbitrage profit at the expense of the tax system, so long as the marginal rates of the transactors are taken as given. All that is required is that the applicable tax rates be specified in advance of entering into the bet.

Allowing the parties to specify the fraction of gains (and losses) to be included in (deducted from) taxable income would not enable them to obtain an arbitrage profit at the expense of the tax system. This result holds even if the inclusion fraction is allowed to differ for the party and counterparty. The essential requirement is that the treatment of gains and losses for a given party be the same and specified before the uncertainty is resolved. (Clearly, if I can decide after the fact whether my position is governed by a red or green contract, I can profit at the expense of the tax system.)

The tax arbitrage at the heart of the analysis in this paper is thus a matter of time, and not risk. The question is what this insight implies for the taxation of complex financial instruments.

\section{Putting Time and Risk Together}

Most financial instruments have both intertemporal and risk aspects. An option is a good example. So too, however, is a long-term bond. Even if there is no risk of default, 
there is a risk of changes in the short-term rates of interest. Thus the value of a long-term bond between issue date and maturity is risky. ${ }^{15}$

Table 8. Illustrative Risky Instruments: Cash Flows to Lender

\begin{tabular}{|r|c|c|c|c|}
\hline Time Point: & 0 & 1 & \multicolumn{2}{|c|}{2} \\
\hline Contingency: & & & Heads & Tails \\
\hline Time 0 Unit Bond & -1 & $1+r_{01}$ & & $1+r_{12}$ \\
\hline Time 1 Unit Bond & & -1 & $1+r_{12}$ & 0 \\
\hline Risky Instrument H & $-z_{0}^{H}$ & & 1 & 1 \\
\hline Risky Instrument T & $-z_{0}^{T}$ & & 0 & \\
\hline
\end{tabular}

We can use the two-period framework to consider the possibilities. Table 8 illustrates a pair of typical risky instruments, absent taxes. One of the instruments pays the holder $\$ 1$ at time 2 if a coin comes up heads. The other instrument pays the holder $\$ 1$ at time 2 if the coin comes up tails. The prices of the instruments, determined in the market, are denoted $z_{0}^{H}$ and $z_{0}^{T}$, respectively, where the subscript indicates the time point at which the value is determined.

It is instructive to consider the effect of variations in the time point at which the uncertainty is resolved. One possibility is that the uncertainty is resolved (the coin is flipped) immediately after the instrument is created and sold, at time 0 . In that case, the positive payoffs of the two primitive bets offered in the financial market are, in effect, OID bonds at time 0 . (The instrument is worthless if the coin comes up on the wrong side.)

15 The modern theory of the term structure of interest rates treats all but the instantaneous current interest rate as stochastic, with a risk premium typically built into the expected return on longer-term instruments. See Cox, Ingersoll and Ross (1985). 
The price of an instrument, say the heads bet, will jump immediately from $z_{0}^{H}$ to either zero or $1 /\left(1+r_{01}\right)\left(1+r_{12}\right)$, depending on the outcome. In either case, the price of the instrument will subsequently appreciate at the risk-free unit bond interest rates until time point 2 .

A second possibility is that the uncertainty is resolved at time point 1 . Just before that moment, each instrument will be identical to what it was at time point 0 , except that the payoff moment will have come closer. Its value at that moment will simply be its initial value times 1 plus the time 0 unit bond interest rate. Just after that moment, it will be known which payoff will occur. It is converted into either zero or a one-period unit discount bond.

The third possibility is that the uncertainty is resolved at time point 2 . Just before that point, each instrument will be indistinguishable from its issue date except that the time of payoff will have arrived. The value of the heads claim, for example, will be $z_{0}^{H}\left(1+r_{01}\right)\left(1+r_{12}\right)$. Upon resolution of the uncertainty, its value will jump to 1 or 0 .

\section{Tax Rules to Prevent Unlimited Tax Arbitrage Profit}

The possible time paths of the value of the alternative instrument under different scenarios about the timing of the resolution of uncertainty suggest what is required to preclude tax arbitrage profit. To test for the possibility of arbitrage profit, the required step is to hedge away the risk (as in the case of the Put-Call Parity Theorem) and determine whether a proposed treatment will eliminate the tax arbitrage potential from the resulting pure intertemporal transaction. Here risk is eliminated by buying one each of the risky instruments. 
One overarching proposition follows immediately from the analysis of the risk-free case:

Barring appropriate adjustments to basis, if the rules are linear, taxpayer option to choose the time to recognize gain or loss will imply the potential for unlimited tax arbitrage profit. We do not need risk to establish this conclusion, although the presence of risk renders difficult fixes based on the market value of the instrument.

The various approaches to deal with the problem of gain recognition may be divided, as in the risk-free analysis, into the single and multiple tax rate regimes.

One Marginal Tax Rate for All Transactors

\section{Mark-to-Market}

Mark-to-market income measurement precludes tax arbitrage profit.

\section{Ignore Intermediate Transactions}

Carrying basis along until maturity of the original instrument should work as well in the presence of risk as in the certainty case. The price of the instrument will reflect the tax advantage of deferral to the lender and its disadvantage to the borrower.

To illustrate, suppose that in the case displayed in Table 8 a lender purchases a unit of risky instrument $\mathrm{H}$ and that the contingency is resolved, with "Tails" as the outcome revealed, immediately after purchase but still at time 0 . The lender's basis is $z_{0}^{H}$. After the outcome is revealed, the instrument is worth 0 . If the lender holds the instrument to maturity, the payoff after tax will be $0-m\left(0-z_{0}^{H}\right)=m z_{0}^{H}$. By the same argument used in the risk-free analysis, this payoff will be worth

$$
m z_{o}^{H} /\left(1+(1-m) r_{01}\right)\left(1+(1-m) r_{12}\right)
$$


in the market at time 0 , after the resolution of the uncertainty. If, alternatively, the lender sells the asset at time 0 , this will be the amount realized because the basis in the asset will be conveyed to the purchaser and deducted at the maturity of the instrument. Since the net present value (at after-tax discount rates) of the two outcomes is the same, there is no payoff (or penalty) to early realization of losses.

\section{Impute Interest Currently}

In applying the technique of imputing interest to the holder of an original issue discount bond in the world of certainty, the payment by the borrower to the lender at maturity gives rise to a reduction in both borrower's and lender's basis to zero, thereby bringing the imputation to an end. These payments are not otherwise reflected in taxable income. There is no current deduction of the payment by the borrower, nor inclusion of amounts received by the lender.

In the world of risk, there is, in addition, settlement of a bet involved in the payments from borrower to lender. Under the usual treatment of bets, the payment from loser to winner is currently deducted by the loser and included by the winner. The question is how one can separate the two (other than by marking to market).

A possible answer is to wait until maturity, along the way imputing, and taxing, interest on basis (with basis adjustment). At settlement time, any amount paid by the borrower in excess of adjusted basis would be deducted by the borrower and included by the lender. Any shortfall of the settlement amount from basis would be deducted by the lender (as a loss) and included by the borrower. 
This relatively straightforward approach would work out well in a world in which the instrument is held to maturity. As in the risk-free analysis, the effect is to eliminate the tax rate from the determination of the value before maturity.

There are two problems presented by sale of the instrument at an intermediate point. One is the potential for shifting gains to low marginal-rate holders and losses to high-marginal rate holders. This does not arise in the one-rate case. The second problem is the potential for cherry picking, which arises because the information about winners and losers generally emerges before the payoff date.

To illustrate, consider the first scenario described above, in which the coin flip takes place at time 0 . For specificity, let us focus on instrument $H$. The outcome of the coin flip is to convert it into one of two risk-free discount bonds, one paying off $\$ 1$ at time 2 , and one paying off 0 . Immediately following the issue of the instrument, the coin is flipped and there is a jump in its market value, up or down, from the issue price, $z_{0}^{H}$, to whatever the value of those discount bonds may be when account is taken of the tax consequences to the seller and buyer.

In what might be regarded as the natural procedure, the OID bonds would be taxed to a subsequent acquirer like any other bond with the same terms, and the seller of the instrument would take into income the proceeds of sale, deducting basis (and thereby reducing to zero the amount on which interest is imputed to the original lender). Since the bond-equivalent will be treated by the new "lender" exactly like a newly issued bond, its market value will have to be either $1 /\left(1+r_{01}\right)\left(1+r_{12}\right)$ or 0 , depending upon the resolution of uncertainty at time 0 . Interest imputation based on the issue price, $z_{0}^{H}$, would contine to be deducted by the borrower (with adjustments to basis). Interest imputed to the new 
lender would be higher or lower, depending on the payoff. At maturity, the payments of 1 or 0 , as appropriate, would be made. For the new lender, the payoff will just equal adjusted basis, so there will be no tax consequences at payoff time (other than elimination of basis and its associated interest imputation). For the borrower the payoff amount will exceed basis in the high-payoff case, resulting in a deduction. In the low-payoff case the payoff amount will be 0 , below basis, resulting in a taxable gain.

The question is, would selling the instrument after the uncertainty is resolved produce a tax advantage? Would it pay, for example, to sell a losing position, thereby accelerating the deduction of basis? We can pose the issue in general terms by supposing that the outcome after resolution of uncertainty at time 0 is some arbitrary amount, $a\left(1+r_{01}\right)\left(1+r_{12}\right)$, payable with certainty at time 2 . Immediate sale (for $a$ by the original lender would give the seller a net pay off $(1-m) a+m z_{0}^{H}$, after taking acount deduction of basis. Holding to maturity would imply a larger basis deduction at that time, worth $m z_{0}^{H}\left(1+r_{01}\right)\left(1+r_{12}\right)$, but at the price of paying tax on imputed interest in the interim, amounting to $m z_{0}^{H} r_{01}$ at time 1 and $m z_{0}^{H}\left(1+r_{01}\right) r_{12}$ at time 2. The extra basis deduction exactly compensates for the extra tax along the way, but the gross sale proceeds grow to $a\left(1+r_{01}\right)\left(1+r_{12}\right)$, that is, on before-tax terms, resulting in a payoff to deferral whenever $a$ is positive.

An alternative treatment would be to require carryover of basis until maturity, much as under the "ignore intermediate transactions" approach, but with the addition of interest imputation to basis. The purchaser would be obliged to carry the basis, with its imputed interest, and would take the consequences at maturity of the gain or loss in 
settlement with the issuer. In other words, the purchaser would step into the shoes of the original lender. The further new twist is that any excess of the amount paid by an acquirer over the basis taken over would be treated as settlement of a bet, deducted by the acquirer and included by the seller. Because the tax rate is the same for all participants, the result is that the net flow of taxes associated with the instruments in the market would be independent of intermediate transactions in those instruments. The outcome would be the same as under obligatory holding to maturity.

Unlike the case of imputation of interest under certainty, which resulted in the market prices of all instruments being independent of the tax rate, under this generalization of the approach to the case of risk, "the" tax rate would manifest itself in the market prices of assets for which gain or loss has been determined.

\section{Impute Interest on Realization}

Imputing interest on realization should also work as well in the risky as in the riskfree setting. This is the essence of the Auerbach analysis. ${ }^{16}$ Recall that basis is dispensed with in this approach. Instead, the actual payoff is treated as having been accumulated at the risk free rate from the acquisition date to the realization point. Typically, the result would be a lower tax than under a mark-to-market regime on the holder of the winning risky instrument (who is not taxed on the gain, but simply on the implied past interest), offset by higher taxes on the loser. This becomes clear when it is noted that, for an instrument with any positive value, no matter how far below basis, the loser would owe tax on realization.

16 For details of the argument, see Auerbach (1991). 


\section{The Multiple Tax Rate World}

In the multiple tax rate world without risk, we saw that a stronger condition than symmetry, namely consistency, was generally required to preclude tax arbitrage profit. The general conclusion is that those techniques for dealing with the realization problem for capital gains that give rise to the independence of the market value of an instrument of the single rate of tax in the one-rate world continue to work out in the multiple tax rate world, even with risk.

Of the techniques considered thus far, only the mark to market and the Auerbach method of retrospective allocation of gain pass the test. Ignoring intermediate transactions and imputing interest currently work only with a uniform tax rate, because under these methods the tax rate affects equilibrium asset prices. The essential reason the mark to market and Auerbach methods work is that they eliminate any timing advantage in the risk-free case and they imply that the same effective rate of tax will apply to gains and losses due to the resolution of contingency.

\section{A General Procedure for Taxing Financial Instruments}

The conclusion of the discussion above is that, with zero transactions cost and multiple marginal rates of tax (and positive interest rates), the only approaches thus far suggested that would permit a linear tax are the mark-to-market and Auerbach look-back methods. Of these, only the Auerbach look-back method is based on realization. If it is true, as is generally accepted, that the mark-to-market approach is practically infeasible, the implication would be that the Auerbach look-back system is the only practically feasible approach thus far discovered that will "work." The question is, is it the only such approach, period; is it necessary as well as sufficient? 
The answer is no. As argued above, risk presents "no problem" provided the tax rate that applies is specified in advance of its resolution. The difficulty with cherry picking is that it allows the parties to a financial instrument, in effect, to decide after the fact what tax will apply. They choose a high tax rate to apply to losers (deduction) and a low tax rate to apply to winners (deferral).

A system that will work must (a) result in consistent taxation of pure timing and (b) establish in advance the tax rate that will apply to any taxpayer's gain or loss due to the resolution of contingency. If the parties are to have a choice of when to realize, the trick is to find a way to make the parties commit to an effective tax rate in advance.

\section{The Case of a Risk-Free Term Structure}

To develop rules sufficient to address both problems it will be convenient to start with the assumption that the future short-term interest rates are known with certainty in advance. Other returns may be risky, but the short-term interest rate at each date is predictable with certainty. In that case, the term structure of interest rates (the implicit rates of return on zero-coupon bonds with different maturities) would fully inform about the path of future short-term rates.

\section{The Proposed Approach When There Is No Cash Flow before Realization}

The first step under the proposed approach is to specify at the time a taxpayer takes a position in a financial instrument (so at the of writing the contract or on acquiring the instrument by purchase), a gain reference date (GRD) and a gain tax rate (GTR). (Although I call these "gain" rate and date, it is intended that they apply to losses as well; "gain" might be negative.) The specification of gain tax rate and gain reference date is arbitrary, and they need not be the same for the party and counterparty to an instrument. 
GRD and GTR could be specified by the tax authorities. They could even be freely chosen by the taxpayer. In practice one might want to render these foreign ideas more digestible by restricting the specification in some way. For example, the gain tax rate might be the investor's marginal rate in the preceding year; the gain reference date might be specified as the date of acquisition of the instrument. The key requirement is that the date and rate be out of the taxpayer's control before new information about the instrument comes in. The gain reference date and the gain tax rate are used only for determining that party's tax consequences of gains and losses on the instrument.

Up to the GRD, a taxpayer who acquires an instrument will be taxed on interest imputed to basis (with a basis adjustment for the imputed amount), exactly as discussed above in the case of the world without risk. A taxpayer with a net liability (the "borrower") will obtain a deduction for imputed interest and corresponding basis adjustment. The new element is that there is, at the GRD, a special one-time adjustment to the basis for imputing interest. At that point the basis jumps to the value that would have to have prevailed to grow at the unit bond rates to the actual realization price at the realization date. Since this amount is not known until realization, this part of the interest imputation has to be worked out after the fact. (In the event of realization before the GRD another procedure has to be used to make sure the interest imputation results are the same as they would be if the asset had been held to the GRD.)

The gain tax applies as of the GRD to the jump in basis as of the GRD just described. The sale of the instrument, regardless of when, will give rise to a tax on the seller of any gains (with a tax rebate in the event of loss) at the GTR, as though all the gains relative to basis, adjusted for interest imputed without taking into account the 
special, one-time adjustment, had occurred at the GRD and had been realized then. Under this approach, the extent of gain is determined by the taxpayer decision to realize, the revealed amount of gain or loss being projected forward or backward to the GRD at the going interest rates.

The idea of this system is, I think, fairly simple, even if the details seem somewhat complex, treated as a cookbook recipe. Apparent complexity arises from the steps needed to arrange the gain tax so that it were as if all the gain occurred at the GRD and to implement the imputation of interest to basis. Here are rules that will do this:

- In all cases, interest is imputed to basis and subjected to tax until the point of realization. Basis is adjusted upward by the imputed interest. (For a liability, the imputation results in a deduction.)

- If the realization is at the $G R D$, the excess of the realized proceeds over adjusted basis is subject to tax at the GTR. In the event of a loss, there is a credit of the GTR times the loss.

- If the realization is after the GRD, there is a look-back calculation. The excess of realized proceeds over adjusted basis is projected back to the GRD at the before-tax rate of interest. The gains tax that would have been due at that point is calculated by applying the GTR to the back-cast amount. The implied tax liability as of the GRD is brought forward with (deductible) interest and paid at the realization point. In the event of a loss, there is a credit instead of a positive tax.

Also, the basis to which the interest imputation applies is adjusted retroactively upward by the amount of the gain as of the GRD. (It is as though the basis had been marked to market at that point, except that the value used is the back-cast amount, 
rather than the actual market value, which is not observed.) So there is imputed to the years between the GRD and the realization year interest on the gain, with yearly compounding. Implied changes in tax for past years are brought forward with (deductible) interest and paid at the realization point. (In the event of a loss, the extra interest income is negative; that is, there is imputed to the years between the GRD and the realization year a deduction of interest on the loss, with yearly compounding.)

- If realization is before the GRD, the gain or loss relative to adjusted basis is projected to the GRD at the going rates of interest. At the GRD, the gain thus projected is taxed at the GTR (for a loss there is a credit). ${ }^{17}$ Between the realization date and the $\mathrm{GRD}$, the seller is supposed to continue to get the benefit of deferral (a negative benefit in the case of a loss). So between the realization date and the GRD the taxpayer is allowed a deduction of interest imputed to the amount of the gain (adjusted each year by the amount of interest deduction). (The idea is to offset, until the GRD, the part of the imputation of interest to basis in a new position taken with the sales proceeds that is the result of the realization.) In the case of a loss, there is an annual imputed interest inclusion.

The choice of GRD and GTR together determine the effective rate of tax on gains and losses. For any given date of realization, the variation in the GRD alters the taxation 
of gains and losses because the rules adjust the basis to which interest is imputed as of the GRD. Using continuous discounting, and assuming constant marginal tax rate on interest and a constant interest rate on the continuous equivalent of the unit bonds, the tax payable at realization date, $s$, on an extra dollar's worth of sales proceeds is $1-(1-G T R) e^{-m r(s-G R D)}$. Given the realization date, $s$, an increase in the GRD makes this effective tax rate on gains smaller. ${ }^{18}$ (For further details on the continuous discounting version of the rules, see the Appendix.)

17 A peculiarity of this procedure is that the tax consequences of realization are not fully known until the GRD. This is a consequence of not knowing the taxpayer's marginal rates (and perhaps the current interest rates) for the intervening period. If the marginal tax rates and current interest rates period by period are known in advance, the tax on the gain could be brought to the realization date, with appropriate discounting. In that case, the basis for the imputed interest deduction would be reduced by the amount of the gain tax paid at realization. (The idea of the interest credit is to give the holder the same amount of "tax free" accumulation as would obtain if the asset had been held to the GRD.)

18 In the case of realization at time $s$, an extra dollar realized implies an extra gain tax liability (reckoned as of the GRD) of $G T \operatorname{Re}^{-r(s-G R D)}$, where continuous compounding at a constant interest rate, $r$, has been used to simplify the calculations. This amount of tax regarded as payable at the GRD translates into an extra tax at the realization date of $G T R e^{-r(s-G R D)} e^{(1-m) r(s-G R D)}=G T R e^{-m r(s-G R D)}$, where a constant marginal tax rate, $m$, is assumed. There is an additional effect due to the revision in the basis for imputation, starting at the GRD. (The description applies to a realization after the GRD, but the mathematical expressions apply as well for a realization before the GRD.) The extra basis is $e^{-r(s-G R D)}$, implying a flow of extra interest imputed of $r e^{-r(s-G R D)} e^{r(t-G R D)}=r e^{r(t-s)}$ starting at $t=$ GRD and running up to the realization date, $s$. This, in turn, implies an extra flow of tax liability, $m r e^{r(t-s)}$, which must be brought forward and paid at $s$. An extra dollar realized at $s$ thus implies an extra amount of tax to be paid at $s$, due to extra interest imputation, of

$$
\begin{gathered}
\int_{G R D}^{s} m r e^{r(t-s)} e^{(1-m) r(s-t)} d t=\int_{G R D}^{s} m r e^{m r(t-s)} d t \\
=\left.e^{m r(t-s)}\right|_{G R D} ^{s}=1-e^{-m r(s-G R D)}
\end{gathered}
$$




\section{An Illustration of the Proposed Approach}

To take an illustration, suppose your tax rate is $30 \%$ the going interest rate is $10 \%$ and you have invested $\$ 1000$ in a share of stock this morning. You have established a GRD of one year from now, and a GTR of 50\%. By this afternoon, your stock has jumped to $\$ 1200$. You know that from here on, the stock will yield with certainty the going rate of return on risk-free bonds, with no cash dividends. ${ }^{19}$ Consider the choice of when to sell.

- If you wait one year, your asset will be worth $\$ 1320$. Your basis will be adjusted up to $\$ 1100$, at a cost to you of $\$ 30$ in tax on the imputed interest. The gain calculated at that time will be $\$ 220$, on which you will owe $\$ 110$. You will be left with $\$ 1320-\$ 30$ $\$ 110=\$ 1180$

- If you wait an extra year to time 2 , you will pay tax at the one-year point of $\$ 30$ on imputed interest. In order to get everything to one point in time, assume you borrow the $\$ 30$. Your position at the end of the second year will then be an asset worth $\$ 1452$ and a liability of $\$ 33$ (bringing with it a $\$ 3$ interest deduction). The basis of the asset will be $\$ 1210(\$ 1000+\$ 100+\$ 110)$ and you will owe tax of $30 \%$ of the second year's imputed interest of $\$ 110$.

Putting the two pieces together, the extra tax due at the realization date due to an extra dollar realized then is $G T R e^{-m r(s-G R D)}+1-e^{-m r(s-G R D)}=1-(1-G T R) e^{-m r(s-G R D)}$.

19 These assumptions are made to allow us to focus on the essential issue of cherry picking. Alternatively, we could specify a hedging transaction that would eliminate any risk of gain or loss on the position, as in the put-call parity theorem, but it would greatly complicate the description. 
Your gain of $\$ 1452$ less $\$ 1210$, or $\$ 242$, will be projected back at the unit bond rate of $10 \%$ one year to the GRD. So you will be treated as having a gain of $\$ 220$ at the GRD. As a consequence of your back-projected gain of $\$ 220$ at the GRD, you will have a $\$ 110$ gain tax liability as of that point. The $\$ 110$ gain tax will be treated as a loan from the government. You will pay it at the 2-year point, plus deductible interest. Your gain tax payment at the 2-year point will thus be $\$ 121$, of which $\$ 11$ is deductible interest.

The extra $\$ 220$ you are treated as having realized at the GRD will also imply a higher basis, by $\$ 220$, for interest imputation from that time forward (one year in this case). So at the 2-year point you will have total imputed interest received of $10 \%$ of $\$ 1100$ plus $\$ 220$, or $\$ 132$, total interest to pay of $\$ 3$ (on the money we assume you will borrow to pay the tax at time 1) plus $\$ 11$ (on the money you are treated as having borrowed to pay the tax on gain at the GRD); since the interest paid is deductible, you will have a net income tax liability of $30 \%$ of $\$ 132-\$ 14=\$ 118$, or $\$ 35.40$.

Your position at the 2-year point will then be $\$ 1452$ (from selling the asset)-\$121 (tax on gain plus interest for the deferral of one year since the GRD)-\$33 (repay, with interest, the money borrowed to pay the income tax at time 1) $-\$ 35.40$ (income tax at time 2$)=\$ 1262.60$. This is the same position you would be in as under the other scenarios: $\$ 1180 \times 1.07 \%=\$ 1262.60$.

- If you realize now, you will realize $\$ 1200$, for a gain of $\$ 200$ over your acquisition cost, which is also your basis. For tax purposes, you will be treated as though the gain (inflated by the interest rate) actually occurred as a jump a year from now. In the meantime, you will qualify for an interest deduction on $\$ 200$, and you will earn interest 
on the $\$ 1200$ realized proceeds. So at year end you will have $\$ 1320$, including $\$ 120$ in interest earned on your $\$ 1200$. There will be an imputed interest deduction of $\$ 20$, so for tax purposes you will have net interest income of $\$ 100$, on which you will owe $\$ 30$ in income tax. In addition, your gain will be calculated as $\$ 200$ times $110 \%$, resulting in $\$ 110$ in gains tax. The net proceeds will be the same as if you waited to the GRD to realize: $\$ 1320-\$ 30-\$ 110=\$ 1180$.

If, in this illustrative case, you had chosen the same GTR but a GRD of two years from now, the results would be different. As in the example, you would be indifferent whether to realize immediately or at some time before or after the GRD. But the amount at the two-year point that would be common to your projections of the consequences of realizing at different dates would be $\$ 1452$ (from selling the asset)- $\$ 121$ (tax on the gain of $\$ 242$ ) - $\$ 33$ (repay, with interest, the money borrowed to pay the income tax at time 1) $\$ 32.10$ (income tax at time 2 on $\$ 110$ in interest imputed to the adjusted basis at time 1 of $\$ 1100$ less $\$ 3$ in interest paid on borrowing) $=1265.90$ instead of $\$ 1262.60$. The reason for the difference is that you save on extra basis of $\$ 110$ that would have come into the interest imputation calculation at the one-year point if that had been your chosen GRD.

The choice of GRD and GTR thus does "matter" ex post. In the event of a gain, the outcome with a two-year GRD would be better than with a one-year GRD. Similarly, in the event of a gain, a lower GTR would be better than a higher GTR. But these plusses are exactly balanced by the minuses in the event of a loss. Then a later GRD is worse and a lower GTR is worse.

To spell out how a loss would be handled, take the original fact situation (income tax rate of $30 \%$, interest rate of $10 \%, \$ 1000$ invested in a share of stock this morning, 
GRD one year from now, and a GTR of $50 \%$ ), except the share falls to $\$ 800$ in the course of the day. And suppose you sell immediately. Under the rules, interest is still imputed for one year on $\$ 1000$, but you get a deduction for interest imputed on $\$ 800$, for net imputed interest of $\$ 20$. The $\$ 800$ has, in the meantime earned $\$ 80$ in interest, so you owe tax of $\$ 30$ on the sum of imputed and actual interest income. Basis and sales proceeds are projected to $\$ 1100$ and $\$ 880$, respectively, so your loss is treated as $\$ 220$ at time 1, saving you $\$ 110$ in tax. Your net position is then $\$ 880$ (proceeds of sale of stock plus interest) - $\$ 30$ (tax on interest) $+\$ 110$ (tax saving due to capital loss, assumed refundable or otherwise usable to offset other taxes) $=\$ 960$.

If you wait a year to realize, you can anticipate the asset being worth $\$ 880$. You will owe $\$ 30$ in interest imputed to your basis of $\$ 1000$, which is adjusted to $\$ 1100$. You will have a loss of $\$ 220$, qualifying you for $\$ 110$ in tax savings. Your net position will be $\$ 880$ (proceeds of sale of stock) - $\$ 30$ (tax on imputed interest) $+\$ 110$ (tax saving due to capital loss, assumed refundable or otherwise usable to offset other taxes) $=\$ 960$.

If you had instead chosen the date of acquisition of the asset as the GRD, you would have a tax saving at that point of $\$ 100$ in the case of immediate realization of the loss. You would then have $\$ 900$. A year from now you would have $\$ 990$ less tax of $\$ 27$ on $\$ 90$, or $\$ 963$ (i.e., more than with the later GRD). In the case of waiting a year, you could anticipate the asset being worth $\$ 880$. The loss would be back-cast to $\$ 200$ at the acquisition date; the tax saving of $\$ 100$ would be brought forward with (taxable) interest to year 1. You would also be imputed an interest deduction on $\$ 200$. Your net position would be $\$ 880$ (sales proceeds) $+\$ 110$ (capital gains tax saving due to loss, plus interest) - $\$ 30$ (tax on imputed interest on original basis) $-\$ 3$ (tax on interest paid on capital gains 
tax saving) $+\$ 6$ (tax saving due to back-cast adjustment in basis for imputation) $=\$ 963$. Similarly, choosing a higher GTR would turn out, after the fact of a loss, to work to your advantage.

\section{Comments on the Proposed Approach}

Both new elements of the proposed approach, the GTR and the GRD, serve the same function: to specify in advance of the resolution of uncertainty the rate of tax that will apply to the "bet" aspect of an instrument with contingent returns. (The treatment of the intertemporal aspect is dealt with by the imputation of interest to basis and interest charges for any postponement of tax payments.) The GTR obviously serves this function. But the GRD also plays a role in determining the effective taxation of gains and losses. The farther in the future is the GRD, the greater is the extent of deferral advantage conferred on winnings (and disadvantage on losses).

Given the option to set the GTR, the option to set the GRD is essentially cosmetic. Considerations of simplicity and the risk of non-arms length circumstances might argue for setting the GRD at 0 (relative to acquisition). This implicitly treats all gain as occurring at the moment after acquisition of the asset. A GRD of 0 eliminates any problem of projecting gain or loss from a pre-GRD realization point.

The policy interest in the GTR and GRD is an open question that invites further exploration. There is no obvious case for allowing the taxpayer free choice. I have suggested free choice as an option simply to emphasize the arbitrary role played by these parameters. If there is the possibility of non-arms length terms of financial instruments, it might be desirable to impose a requirement of the same GTR and GRD on both sides of a 
bilateral transaction. (A simple way to do this would be to specify a uniform GTR and GRD at the acquisition date.)

A similar observation applies to the possible extension of the proposed approach to positions other than in bilateral financial instruments. The owner of a small business or piece of real estate, for example, is perhaps best understood as obtaining a form of "labor income" in gains realized from the enterprise or other property. In such cases, policy might imply setting the GTR in some appropriate relationship (e.g., equality) with the rate of tax on compensation.

I have argued that the proposed approach is sufficient to satisfy the requirements of a linear income-measurement system. An open question is whether, among realization methods, the proposed approach is necessary, i.e., encompasses all the possibilities. Is there another realization method that works and cannot be described in terms of the proposed approach's GRD and GTR? I believe the answer is no, but I have not proved it.

An interesting instance of this question is the connection of the proposed approach to the Auerbach method, which we know works. The Auerbach method treats the sales proceeds on realization as all due to accumulation of gain at the going interest rate since the acquisition date. Only that gain is subject to tax (with appropriate look-back interest charges). Although it may, at first sight, appear different (since there is no current imputation of interest to basis), the Auerbach method is effectively a special case of the proposed approach, where the GRD is 0 and the GTR is also 0: gains and losses are taxed 
at a zero rate as though occurring a moment after acquisition; interest is imputed to the implied basis and taxed in retrospect. ${ }^{20}$

\section{Treatment of Intermediate Cash Flows}

Any cash inflow from the "borrower" to the "lender" side of an instrument (an interest payment received, for example) between the acquisition date and the time of realization would result in a reduction to basis. The cash outflow (payment of interest, for example) would reduce the liability basis of the "borrower".

Sale of a fractional interest in an instrument could be handled by apportioning the basis between the interest sold and the interest retained. Treatment of the sale of any more complex claim to the instrument (selling off the rights to the dividends, for example) would require more thought. Probably such a transaction would be best treated as the issue of a new instrument.

\section{The Proposed Approach and Correctness}

Since it relies on imputation of interest, the proposed approach suffers from the general shortcoming of interest as a measure of income: failure to adjust for inflation. If inflation-adjustment were implemented, or for the case of no inflation, the interest

${ }^{20}$ Under the Auerbach approach, all the imputation of interest takes place retrospectively at the time of realization, working back to a kind of reconstructed basis from the amount realized. It does not matter whether the asset is sold at a gain or loss. In the proposed approach, there is interest imputed from the moment of acquisition, but the basis for imputing interest is retrospectively adjusted, from the GRD forward, at the time of realization. So if the GRD is the acquisition date, the effective imputation of interest occurs as under the Auerbach approach. Since under the Auerbach approach the amount of gain or loss is irrelevant, the GTR is effectively zero. This is may be seen in the continuous-compounding example of footnote 18: if GTR $=\mathrm{GRD}=0$, the only extra tax at the time of realization is the "correction" to the imputation of interest since acquisition. This is, effectively, the Auerbach result. 
imputation would produce a correct measure of income for riskless instruments. In fact, for such instruments, the path of taxable income would be the same as under a mark-tomarket regime.

For risky instruments, however, there would be no connection between the path of taxable income and the path of market value of the instrument. There would, for one thing, be a one-time extra liability (or rebate) at the moment of realization (as in the case of realization with conventional income-tax rules). Furthermore, there would be no necessary relationship between the discounted value of tax liability under the proposed system and the path of liability under a mark-to-market regime. Nor could there be, since there is no observation of an instrument's market value except at the moments of its acquisition and sale.

There would, however, be equivalence of the proposed method's results and those obtaining under mark-to-market accounting. Offered a choice at the time of acquiring the asset, the taxpayer should be indifferent between any particular specification of the proposed method (GTR and GRD) and mark-to-market accounting. (Strictly speaking, to establish indifference with full generality requires a sufficiently full set of contingent instruments to permit the taxpayer to take any desired position in the risk aspects of an instrument.) The correctness thus resulting from the proposed method is akin to that that would be produced by taxation of nominal interest income in a single-tax rate world. The 
outcome for the taxpayers would be the same as that with income correctly measured for tax purposes, even though the actual flow of tax liabilities would be different. ${ }^{21}$

\section{Extending the Analysis to Uncertain Future Short-Term Rates}

\section{The Term Structure of Interest Rates with Uncertain Short-Term Rates}

As I have pointed out above, the imputation of the yield to maturity to holders of a long-term instrument will not, in general, yield the right tax result, where "right" refers to a result that precludes arbitrage profit opportunities. The exception is the case of shortterm rates that are known to be constant. When the term structure of interest rates results simply from the variation over time in the short-term rate, but not from uncertainty about that variation over time, the imputation of the current short-term interest to basis (rather than yield to maturity) does produce the right result. The holder of a long-term zerocoupon bond will be fully taxed by the imputation of interest to basis at the going rate. The adjusted basis on a discount bond will always equal its current market value, so the effect is the same as a mark-to-market rule.

When, however, the short-term rates are themselves uncertain (even if they are expected to be constant), this will not, in general, be the case. ${ }^{22}$ Instead the machinery

21 As in that case, to complete the establishment of equivalence from the point of view of everyone, including the government (representing the rest of the taxpayers), requires the government to take a position appropriately offsetting that taken by the taxpayer. To illustrate, in the example of the bets using red and green contracts, if one side of the bet chooses red and the other green (and both have the same tax rate), the government would need itself to write a taxable contract on the same event to avoid any net cash flow due to the bet.

22 Profit from buying and selling as the price of longer-term instruments vary with changes in short-term rates is the main focus of Strnad's (1995) analysis. 
described in the previous section comes into play and gives rise to taxation of gains and losses on the instrument that are contingent on the movement of short-term rates. ${ }^{23}$

Although it is beyond the reach of this paper to address the issues in depth, I describe in this section the way the proposed method of taxing financial instruments would apply to a long-term discount bond when future short-term rates are not known. In doing so, I would reemphasize that the issue is not correctness of the measure in some absolute sense. Rather, the objective is a linear income measurement system. The theme of the design of rules is consistency of the taxation of all financial instruments with the taxation of the duplicating sequence of unit bond transactions.

U.S. income taxation already makes use of standardized interest rates (the Applicable Federal Rates) for various purposes. These rates are identified for various terms of the instruments in question. As has been shown, strictly speaking, these rates are not quite what are called for. The rates observed for contracts of any length blend different underlying short-term rates that correspond to the simple model's unit bonds' interest. Furthermore, the future values of those short-term rates are not known with certainty and the longer-term rates reflect that uncertainty. So they represent a blend of pure intertemporal returns and risk premia. It is for this reason that I was a bit vague in referring, in the introductory discussion of tax arbitrage, to the sequence of transactions in short-term bonds required to duplicate a discount bond for tax arbitrage purposes.

${ }^{23}$ Taking into account that the future unit bond rates are not known adds (to the unknown future tax rates) another reason to wait until the GRD to complete the taxation of the sale of an instrument before the GRD. It is likely, however, that the equivalent at the time of realization could be derived from options prices. I have not tried to work out the details. 
Table 9. Term Structure Illustrated

\begin{tabular}{|l|c|c|c|c|c|}
\hline \multicolumn{5}{|c|}{ Cash Flows to Lender } \\
\hline Time Point: & 0 & \multicolumn{2}{c|}{1} & \multicolumn{2}{c|}{2} \\
\hline Contingency: & & Heads & Tails & Heads & Tails \\
\hline Time 0 Unit Bond & -1 & $1+r_{01}$ & $1+r_{01}$ & & \\
\hline Time 1 Unit Bond & & -1 & -1 & $1+r_{12}^{H}$ & $1+r_{12}^{T}$ \\
\hline Discount Bond & $-z_{02}$ & & & 1 & 1 \\
\hline Risky Instrument H & $-z_{0}^{H}$ & 1 & & & \\
\hline Risky Instrument T & $-z_{0}^{T}$ & & 1 & & \\
\hline
\end{tabular}

The story is illustrated in Table 9. Here the uncertainty refers to the unknown interest rate on the time 1 unit bond. The events, "Heads" and "Tails," referred to in the columns for times 1 and 2 are the same ones. That is, there is a single coin flip, at time 1 , that determines the short-term interest rate that will prevail between time 1 and time 2 . The two explicitly risky instruments shown in the table pay off at time 1 according to the same coin flip that determines the interest rate on the time 1 unit bond. (They can be thought of as options at time 0 on the time 1 unit bond interest rate.) Also shown is a discount bond that pays 1 at time point 2 , regardless of the outcome of the coin flip. Its payoff is not risky, but its value at time 1 is, because that value depends on the coin flip that determines the short-term interest rate then. At time 0 , the newspapers would report $r_{01}$ as the interest on a bond with one-year maturity, and the yield to maturity of the discount bond, based on its price, $z_{02}$, as the interest on a bond with two-year maturity. Notice that the actual unit bond interest at time $1, r_{12}$, is not known at time 0 .

It is not possible to duplicate the cash flows from the discount bond by a planned sequence of unit bond transactions. If I buy $z_{02}$ time 1 unit bonds and reinvest the payoff 
from them in time 2 bonds at time 1 the amount $I$ will have at time 2 will not be a certain amount, but rather an amount that will depend on the outcome of the coin flip. To obtain a certain return at time 2 , other than by buying the discount bond, I must purchase at time $01 /\left(1+r_{12}^{H}\right)$ units of risky instrument $\mathrm{H}$ and $1 /\left(1+r_{12}^{T}\right)$ units of risky instrument $\mathrm{T}$. By reinvesting the payoff at time 1 in the time 1 unit bond, a certain outcome of 1 at time 2 is assured. Thus, if the coin comes up heads at time 1, the payoff from the position in the package of risky instruments is $1 /\left(1+r_{12}^{H}\right)$ (instrument $\mathrm{H}$ pays off 1 per unit, and instrument $\mathrm{T}$ pays off 0 ). Reinvesting the proceeds in the time 1 unit bond generates an outcome $\left(1 /\left(1+r_{12}^{H}\right)\right)\left(1+r_{12}^{H}\right)=1$ at time 2 .

For consistency (i.e., to eliminate the potential for arbitrage profit), the tax liability of the person who takes the direct route to a certain $\$ 1$ at time 2 by purchasing the discount bond must be the same as that of one who buys the appropriate duplicating package of risky instruments and unit bonds through time. The precise meaning of "the same" merits closer examination, but the condition is clearly met if the cash tax liability is the same at every point in time and under every contingency.

The fixed point of this situation is the tax treatment of the unit bonds, period by period. A sequence of cash flows identical to a time 0 unit bond can be obtained by purchasing $1+r_{01}$ units of each of the two risky instruments. An arbitrage profit opportunity will be available unless the package is taxed the same as the time 0 unit bond (thus integrating the taxpayer's positions in the two instruments). Applying to the contingent returns the system discussed in the previous section, using the time 0 unit bond rate to adjust for timing, will produce the desired tax outcome. 
To illustrate the working of the system, start with the condition for financial market equilibrium in the absence of taxes. Since the outcome is a certain payoff of $\$ 1$ at time 1 , the position consisting of one unit of each of the risky instruments can be financed by borrowing the purchase price of the position, $z_{0}^{H}+z_{0}^{T}$, in the form of the time 0 unit bond. The repayment due at time 1 will be $1=\left(z_{0}^{H}+z_{0}^{T}\right)\left(1+r_{01}\right)$, so $\frac{1}{\left(1+r_{01}\right)}=z_{0}^{H}+z_{0}^{T}$. Now suppose there is a tax and the person in our illustration elects a GRD of time 1 and a GTR of $50 \%$ to apply to the package of risky instruments acquired at time 0 . In the case examined here, the uncertainty is resolved at time point 1 , when the coin is flipped. Until then, the instruments increase in value at the time 0 bond rate. If the prices are those determined without consideration of taxes, at time 1 the investor will have no profit apart from possible tax considerations. There will be interest imputed to basis of $\left(z_{0}^{H}+z_{0}^{T}\right) r_{01}$ but this will be matched by the deduction of interest paid on the money borrowed to buy the risky instruments. For tax purposes, the gain at time 1, which is the chosen GRD, will be the market value of the position, 1, less the adjusted basis, $\left(z_{0}^{H}+z_{0}^{T}\right)\left(1+r_{01}\right)$. This difference will be zero if the assumed prices prevail. So they will be equilibrium prices, and there will be no tax due on the position.

What about the tax results of buying the equivalent to the time 2 discount bond in the form of the appropriate position in risky instruments, combined with investment of the payoff at time 1? Suppose again that the tax scheme works and that the pricing in the absence of taxes prevails in the presence of taxes. Then we know that ( 12 ) holds.

$$
\left(1 /\left(1+r_{12}^{H}\right)\right) z_{o}^{H}+\left(1 /\left(1+r_{12}^{T}\right) z_{o}^{T}=z_{02}\right.
$$


Consider the case that the coin comes up heads. Applying the same rules, there is a taxable gain at time 1 on the position in instrument $\mathrm{H}$ equal to ( 13 )

$$
\left(1 /\left(1+r_{12}^{H}\right)\right)\left(1-z_{0}^{H}\left(1+r_{01}\right)\right)
$$

and a gain (negative) on the position in instrument $\mathrm{T}$ equal to ( 14 )

$$
\left(1 /\left(1+r_{12}^{T}\right)\right)\left(0-z_{0}^{T}\left(1+r_{01}\right)\right)
$$

for a net taxable gain overall of ( 15$)$.

$$
\left(1 /\left(1+r_{12}^{H}\right)\right)\left(1-z_{0}^{H}\left(1+r_{01}\right)\right)+\left(1 /\left(1+r_{12}^{T}\right)\right)\left(-z_{0}^{T}\left(1+r_{01}\right)\right)
$$

In general, the net of the two gains will not be zero and a tax payment or refund, at the GTR, will be due.

Applying the same method to the time 2 discount bond would have the same tax consequences, given the same choice of GRD and GTR, if the bond were sold at time 1, with the proceeds reinvested in the time 1 unit bond. It may be less obvious that the result will be the same if, instead, the bond is held until maturity. Under the rules, and still assuming the coin comes up heads, the interest rate used for imputing income to the bondholder will be $r_{01}$ in the first period and $r_{12}^{H}$ in the second. At time 2 the bondholder will be treated as having gain $1-z_{02}\left(1+r_{01}\right)\left(1+r_{12}^{H}\right)$. The gain will be "discounted" to time point 1 , treated as $\frac{\left(1-z_{02}\left(1+r_{01}\right)\left(1+r_{12}^{H}\right)\right)}{1+r_{12}^{H}}$ at that point. We can substitute the candidate equilibrium relationship ( 12 ) into the expression for gain, yielding ( 16 ),

$$
\begin{gathered}
\left.\frac{1}{1+r_{12}^{H}}-\left(\left(\frac{1}{1+r_{12}^{H}}\right) z_{0}^{H}+\left(\frac{1}{1+r_{12}^{T}}\right) z_{0}^{T}\right)\right)\left(1+r_{01}\right)= \\
\frac{1}{1+r_{12}^{H}}\left(1-z_{0}^{H}\right)\left(1+r_{01}\right)-\left(\frac{1}{1+r_{12}^{T}}\right) z_{0}^{T}\left(1+r_{01}\right)
\end{gathered}
$$


which will be seen to be identical to ( 15 ), the gain on the position in the risky instruments used in the duplicating sequence of transactions. The results are thus the same, after all taxes, of holding the time 2 discount bond and the equivalent sequence of a package of risky instruments at time 0 followed by reinvestment of the proceeds at time 1 to obtain a certain $\$ 1$ at time 2 .

\section{Conclusion}

The approach to realization in the existing income taxation of financial instruments renders inevitable the complexities I describe as nonlinearity. In a general sense, this is well known. I have suggested that the fundamental difficulty is dealing with the intertemporal aspects of income accounting (the reward to waiting) rather than the challenges of uncertainty (the reward to risk-bearing). The present analysis implies that the intertemporal problems may be more serious than may have been thought (as reflected in shortcomings of the rules for instruments with fixed and determinate returns), whereas the treatment of risk (the rules for contingent returns) is in a sense simple.

It is, however, the element of uncertainty that gives rise to realization accounting. We cannot record what we do not yet know. In this paper I conclude that the only approaches that would make realization accounting "work" involve virtually universal application of "the retrospective allocation of gain" and, especially, "the imputation of interest at a standard rate" alluded to by Warren.

In the world of zero transactions cost examined in this paper, there is no substitute for nonlinearity of the income measurement system (such as the limit on the deduction of capital losses) barring near-universal application of "interest at a standard rate" to basis, retrospectively if need be. The only instruments for which what is labeled "interest" in the 
contract is the amount subject to tax are the unit bonds. These are the default-risk free instruments against which tax arbitrage is constructed. (I do not think these "standard" instruments need to be free of risk, default or otherwise, but it would greatly complicate the story to spell out why.) For all the other instruments, including most of those presently regarded as unproblematic (fixed-return assets), either mark-to-market taxation or imputation of interest to basis is required. Furthermore, since essentially all other instruments are risky, relative to the unit bonds, for all other instruments, either mark-tomarket taxation or the realization rules described in this paper must be applied.

One implication is that, if it is desired to have a linear income measurement system, considerations of transactions cost must enter the design of rules. Another, more radical, thought is suggested. Assuming the taxation of interest income is regarded as worth the candle, perhaps consideration should be given to truly universal application of a standardized rate of return to basis (with the sort of realization rules described in this paper). There would be no taxation of interest as observed in the market (no unit bonds). That would make it a simple matter to adjust basis for inflation, and probably come very much closer to a true income tax than is presently achieved by our hybrid rules. 


\section{Appendix: A Continuous-Discounting Version of the Proposed Rules}

Some readers may find helpful a demonstration using continuous discounting that the proposed rules render the taxpayer indifferent to the timing of realization when it is assumed that the asset in question will increase in value at the unit bond yield. Consider the taxpayer's decision to postpone realization from some time, $s$, to some future time, $s^{\prime}$. (To simplify matters, assume that both times are after the GRD for the instrument in question. The mathematical expressions developed in this appendix apply as well for a realization before the GRD.) As outlined in footnote 18 , in the case of realization at a time $s$, an extra dollar realized implies an extra gain tax liability at the realization date of $1-(1-G T R) e^{-m r(s-G R D)}$, where there is continuous compounding at a constant interest rate, $r$, and where a constant marginal tax rate, $m$, is assumed.

If an asset has value $V(s)$ at time $s$, the path of its value at future time, $s^{\prime}$, accruing at the unit bond rate, is described by $V(s) e^{r\left(s^{\prime}-s\right)}$ (assuming throughout no cash flow from the asset). If the asset follows this path, the amount of capital gain as of the GRD will be unchanged by postponing realization. The extra tax due at a future realization date will rise, since there will be more postponement of liability to make up. Suppose, for example, that the current adjusted basis in the asset is $B(s)$, so that the gain, reckoned at the GRD, is

$$
X \equiv(V(s)-B(s)) e^{-r(s-G R D)}
$$

which is also the extra basis subject to interest imputation upon realization. Then the gain tax as of the GRD is GTR.X. This translates into extra tax due at the hypothetical 
later realization date of $G T R \cdot X e^{(1-m) r\left(s^{\prime}-G R D\right)}$, where the liability cumulates at the aftertax interest rate (since interest paid on postponed tax payments is deductible).

The extra interest imputation follows the path $r X e^{r(t-G R D)}$ starting at $t=G R D$ and running up to the realization date, $s^{\prime}$. This, in turn, implies an extra flow of tax liability at time $t$ between $s$ and $s^{\prime}$ of $m r X e^{r(t-G R D)}$, which must be brought forward and paid at $s^{\prime}$, resulting in extra liability at $s^{\prime}$ of

$$
\begin{gathered}
\int_{G R D}^{s^{\prime}} m r X e^{r(t-G R D)} e^{(1-m) r\left(s^{\prime}-t\right)} d t \\
=\left.X e^{r\left(m t+(1-m) s^{\prime}-G R D\right)}\right|_{G R D} ^{s^{\prime}} \\
=X e^{r\left(s^{\prime}-G R D\right)}\left(1-e^{-m r\left(s^{\prime}-G R D\right)}\right) .
\end{gathered}
$$

Putting the two pieces together, the total tax "pulse" at s' is

$$
\begin{gathered}
X e^{r\left(s^{\prime}-G R D\right)}\left(1-e^{-m r\left(s^{\prime}-G R D\right)}+G T R e^{-m r\left(s^{\prime}-G R D\right)}\right) \\
=X e^{r\left(s^{\prime}-G R D\right)}\left(1-(1-G T R) e^{-m r\left(s^{\prime}-G R D\right)}\right)
\end{gathered}
$$

The extra after-tax cash flow at $t$ due to waiting until $s$ ' to realize is the tax on interest imputed to basis,

$$
-m r B(s) e^{r(t-s)}
$$

for $t$ running from $s$ to $s^{\prime}$. The net gain from waiting from $s$ to $s^{\prime}$ is the discounted value (to $s$, at the after-tax rate) of this flow of tax payments and the pulse of realized proceeds of sale at $s$ ' less the pulse of extra tax payments due at $s^{\prime}$,

$$
\begin{gathered}
\int_{s}^{s^{\prime}}\left(-m r B(s) e^{r(t-s)}\right) e^{-(1-m) r(t-s)} d t+ \\
\left(V(s) e^{r\left(s^{\prime}-s\right)}-X e^{r\left(s^{\prime}-G R D\right)}\left(1-(1-G T R) e^{-m r\left(s^{\prime}-G R D\right)}\right)\right) e^{-(1-m) r\left(s^{\prime}-s\right)}
\end{gathered}
$$

less the foregone cash flow (net of taxes) that would have been obtained from realization at $s$, 


$$
V(s)-X e^{r(s-G R D)}\left(\left(1-(1-G T R) e^{-m r(s-G R D)}\right) .\right.
$$

If this total is positive, it pays to postpone realization. If it is negative, it pays to realize immediately. By laborious algebra, making use of the fact that, by definition of $X$, $V(s)-X e^{r(s-G R D)} \equiv B(s)$ this expression for the net current cash flow equivalent at $s$ of waiting to realize from $s$ to $s^{\prime}$ reduces to

$$
\begin{gathered}
V(s)\left(1-e^{m r\left(s^{\prime}-s\right)}\right)-X e^{r(s-G R D)}\left(1-e^{-m r\left(s^{\prime}-s\right)}\right)+ \\
V(s) e^{m r\left(s^{\prime}-s\right)}-X e^{r\left(m s^{\prime}-G R D+(1-m) s\right)}\left(1-(1-G T R) e^{-m r\left(s^{\prime}-G R D\right)}\right)+ \\
-V(s)+X e^{r(s-G R D)}\left(1-(1-G T R) e^{-m r(s-G R D)}\right.
\end{gathered}
$$

which equals, on collection of terms,

$$
\begin{gathered}
V(s)\left(1-e^{\operatorname{mr}\left(s^{\prime}-s\right)}+e^{\operatorname{mr}\left(s^{\prime}-s\right)}-1\right)+ \\
+X e^{r(s-G R D)}\left((1-G T R) e^{-\operatorname{mr}(s-G R D)}-(1-G T R) e^{-\operatorname{mr}(s-G R D)}-\left(1-e^{-\operatorname{mr}\left(s^{\prime}-s\right)}+e^{-m r\left(s^{\prime}-s\right)}-1\right)\right) \\
=0
\end{gathered}
$$




\section{Bibliography}

Auerbach, Alan J., "Retrospective Capital Gains Taxation," American Economic Review, [LXXXI-1] March 1991, pp. 167-178.

Bankman, Joseph, and William A. Klein, "Accurate Taxation of Long-Term Debt: Taking into Account the Term Structure of Interest" Tax Law Review, [XLIV] 1989, pp. 335-348.

Battle, Frank V., Jr., "Bifurcation of Financial Instruments," Taxes, December 1991, pp. 821-833.

Bittker, Boris I., "Equity, Efficiency, and Income Tax Theory: Do Misallocations Drive Out Inequities?" in Henry J. Aaron and Michael J. Boskin, eds., The Economics of Taxation, Washington, DC: The Brookings Institution, 1980, pp. 19-31.

Bradford, David F., "The Economics of Tax Policy toward Savings," in George M. von Furstenberg, ed., The Government and Capital Formation, Cambridge, MA: Ballinger, 1980, pp. 11-71.

Bradford, David F., "Issues in the Design of Savings and Investment Incentives," in Hulten, Charles R., ed., Depreciation, Inflation and the Taxation of Income from Capital, Washington, DC: The Urban Institute, 1981, pp. 13-47.

Bradford, David F., Untangling the Income Tax, Cambridge, MA: Harvard University Press, April 1986.

Bradford, David F., and Kyle D. Logue, "The Effects of Tax-Law Changes on Prices in the Property-Casualty Insurance Industry," Working Paper 5652, National Bureau of Economic Research, July, 1996.

Bradford, David F., and the U.S. Treasury Tax Policy Staff, Blueprints for Basic Tax Reform, 2nd ed., Arlington, VA: Tax Analysts, 1984.

Cox, John C., Jonathan E. Ingersoll, Jr., and Stephen A. Ross, "A Theory of the Term Structure of Interest Rates," Econometrica, (LIII-2) March 1985, pp. 385-408.

Cunningham, Noël B., and Deborah H. Schenk, "Taxation Without Realization: A "Revolutionary" Approach to Ownership" Tax Law Review, [XLVII] 1992, pp. 725-814.

Ferguson, Bradford L., "The Rationales for the Rules: How to Think About Derivatives in the Tax World," Taxes, December 1994, pp. 995-1026.

Hall, Robert E. and Alvin Rabushka, The Flat Tax, 2nd ed., Stanford, California: Hoover Institution Press, 1995. 
Halperin, Daniel I., "Interest in Disguise: Taxing the Time Value of Money," Yale Law Journal, [VC] 1986, pp. 506-552.

Hariton, David P., "The Taxation of Complex Financial Instruments," Tax Law Review [XLIII] 1988, pp. 731-788.

Kaplow, Louis, "Taxation and Risk Taking: A General Equilibrium Perspective," National Tax Journal, (XLVII-4) December 1994, pp. 789-798.

Kau, Randall K.C., "Carving Up Assets and Liabilities -Integration or Bifurcation of Financial Products," Taxes, December 1990, pp. 1003-1014.

Kayle, Bruce, "Where Has All the Income Gone? The Mysterious Relocation of Interest and Principal in Coupon-Stripping and Related Transactions, Virginia Tax Review, (VII) 1987, pp. $303 \mathrm{ff}$.

McCaffery, Edward J., "The Holy Grail of Tax Simplification," Wisconsin Law Review, 1990, pp. 1267-1322.

R. G. Ibbotsen Associates, Stocks, Bonds, Bills and Inflation: 1995 Yearbook, Chicago, IL, 1995 .

Scarborough, Robert H., "Different Rules for Different Players and Products: The Patchwork Taxation of Derivatives," Taxes, December 1994, pp. 1031-1049.

Scarborough, Robert H., "Payments in Advance of Performance," Taxes, December 1991, pp. 798-820.

Scarborough, Robert H., "Risk, Diversification and the Design of Loss Limitations Under a Realization-Based Income Tax," Tax Law Review. [XLVIII] 1993, pp. 679-717.

Shaviro, Daniel N., "Selective Limitations on Tax Benefits," The University of Chicago Law Review, [LVI] 1989, pp. 1189-1260.

Shuldiner, Reed, "A General Approach to the Taxation of Financial Instruments," Texas Law Review, [LXXI-II] December 1992, pp. 243-350.

Shuldiner, Reed H., "Consistency and the Taxation of Financial Products," Taxes, December 1992, pp. 781-792.

Sims, Theodore S., "Long-Term Debt, the Term Structure of Interest and the Case for Accrual Taxation," Tax Law Review, [XLVII] 1992, pp. 313-375.

Sims, Theodore S., "Debt, Accelerated Depreciation, and the Tale of a Teakettle: Tax Shelter Abuse Reconsidered," UCLA Law Review, [XLII-2] December 1994, pp 263-376. 
Steuerle, C. Eugene, Taxes, Loans, and Inflation: How the Nation's Wealth Becomes Misallocated, Washington, DC: The Brookings Institution, 1985.

Strnad, Jeff, "Taxing New Financial Products: A Conceptual Framework," Stanford Law Review, [XLVI] February 1994, pp. 569-605.

Strnad, Jeff, "The Taxation of Bonds: The Tax Trading Dimension," Virginia Law Review, [LXXXI] 1995, pp. 47-115.

U.S. Treasury Dept., Report on Integration of Individual and Corporate Tax Systems: Taxing Business Income Once, Washington, DC: U.S. Government Printing Office, January 1992.

Warren, Alvin C., Jr., "Accelerated Capital Recovery, Debt, and Tax Arbitrage," Tax Law, [XXXVIII] 1985.

Warren, Alvin C., Jr., "Commentary - Financial Contract Innovation and Income Tax Policy," Harvard Law Review, [CVII] 1993, pp. 460-492. 